NBER WORKING PAPER SERIES

\title{
WHY PLANT-LEVEL PRODUCTIVITY STUDIES ARE OFTEN MISLEADING, AND AN ALTERNATIVE APPROACH TO INFERENCE
}

\author{
Hajime Katayama \\ Shihua Lu \\ James R. Tybout \\ Working Paper 9617 \\ http://www.nber.org/papers/w9617 \\ NATIONAL BUREAU OF ECONOMIC RESEARCH \\ 1050 Massachusetts Avenue \\ Cambridge, MA 02138 \\ April 2003
}

We gratefully acknowledge the National Science Foundation for support (grant 421-18 687W0). We have benefited from useful discussions with Tom Holmes, Marc Melitz, Nina Pavcnik, Mark Roberts, Marc Rysman, Sofronis Clerides, Johannes Van Biesebroeck, participants in the 2002 Dartmouth Summer Camp on Firms and Trade, and participants in the December 2002 meetings of the NBER Productivity Group. The views expressed herein are those of the authors and not necessarily those of the National Bureau of Economic Research.

(C2003 by Haijime Katayama, Shihua Lu, and James R. Tybout. All rights reserved. Short sections of text not to exceed two paragraphs, may be quoted without explicit permission provided that full credit including Cnotice, is given to the source. 
Why Plant-Level Productivity Studies are Often Misleading, and an Alternative Approach to Inference

Haijime Katayama, Shihua Lu, and James R. Tybout

NBER Working Paper No. 9617

April 2003

JEL No. L1, O3, L6

\begin{abstract}
Applied economists often wish to measure the effects of managerial decisions or policy changes on plant-level productivity patterns. But plant-level data on physical quantities of output, capital, and intermediate inputs are usually unavailable. Therefore, when constructing productivity measures, most analysts proxy these variables with real sales revenues, depreciated capital spending, and real input expenditures. The first part of this paper argues that the resultant productivity indices have little to do with technical efficiency, product quality, or contributions to social welfare. Nonetheless, they are likely to be correlated with policy shocks and managerial decisions in misleading ways.
\end{abstract}

The second part of the paper develops an alternative approach to inference. Using Steven Berry's (1994, RAND Journal) representation of equilibrium in a differentiated product market, we show how to impute each plant's unobserved marginal costs and product quality from its observed revenues and costs, and how to use this mapping to calculate plant-specific welfare-based performance measures. (Bayesian estimation techniques are required because the vector of unknown parameters is under-identified.) The final part of the paper demonstrates our methodology using panel data on Colombian pulp and paper plants.

$\begin{array}{lll}\text { Haijime Katayama } & \text { Shihua Lu } & \text { James Tybout } \\ \text { Department of Economics } & \text { Charles River Associates } & \text { Department of Economics } \\ \text { Pennsylvania State University } & \text { Boston, MA 02116 } & \text { Pennsylvania State University } \\ \text { University Park, PA 16802 } & & \text { University Park, PA 16802 } \\ & & \text { and NBER } \\ & \text { jtybout@psu.edu }\end{array}$




\section{Overview}

Economists often seek to quantify the effects of a policy or event on the performance of the manufacturing sector. Recurrent questions include: How much, if at all, does trade liberalization improve efficiency? Do multinational investments cause firms to perform significantly better? How big are the efficiency gains from R\&D spending? Are there learning spillovers between firms within an industry? How do entry regulations affect an industry's performance?

To address these issues, many analysts rely on plant- or firm-level productivity analysis. They posit that each establishment's output is a function of the inputs it employs and its productivity level, hereafter indexed by $\phi$. Then, using the available output and input measures, they estimate this function and solve for producer- and time-specific approximations to $\phi$, hereafter, $\widetilde{\phi}$. Finally, looking across producers and/or though time, they correlate $\widetilde{\phi}$ with things like the extent of foreign ownership, intensity of R\&D activity, whether the firms are exporting, rates of effective protection for the firm's product, and whether entry and exit are institutionally constrained.

When output and input characteristics are common across plants, and when data on the physical quantities of these variables are available, the use of $\widetilde{\phi}$-type measures makes good sense. Indeed, most of the methodological literature on this approach to analyzing firm or plant-level performance presumes that these conditions hold. ${ }^{1}$ But in practice, $\widetilde{\phi}$-type measures are more commonly applied to differentiated product and/or differentiated input industries, where the characteristics of products and factor inputs vary

\footnotetext{
${ }^{1}$ Particular attention has been devoted to the issues of how to estimate the functional relationship and how to separate noise from "true" productivity shocks in $\phi_{j t}$.
} 
considerably across producers. ${ }^{2}$ Under these circumstances data on physical volumes are usually unavailable, so analysts are forced to make do with information on the values of production, material inputs, and capital stocks. ${ }^{3}$ The resulting performance measures are therefore, roughly speaking, indices of revenue per unit input expenditure.

Such measures are viewed as a practical solution to the problem of imperfect data, and because they are expressed in relative value terms, they are commonly presumed to avoid the problem of comparing heterogeneous goods and factors. Our first objective in this paper is to argue that this benign view is misguided, and that standard performance measures can be very misleading when applied to differentiated product industries (Section II). Even if the functional relationship between inputs and outputs is precisely estimated, they are contaminated by variation in factor prices and demand elasticities. At worst, they have nothing to do with firms' productive efficiency, product quality or contribution to consumer surplus.

Our second objective is to develop an alternative approach to inference (Section III). Specifically, we view firms' costs and revenues as resulting from a Bertrand-Nash equilibrium in a differentiated product industry, as in Berry (1994), and we incorporate the demand system explicitly in the analysis. This allows us to impute the quantities, qualities, marginal costs, and prices of each good from the observed revenues and

\footnotetext{
${ }^{2}$ A complete list of the relevant studies would take pages. Recent examples include Olley and Pakes (1996), Bahk and Gort (1993), Caves and Barton (1990), Griliches (1986); Aitken and Harrison (1999), Tybout et al (1991); Tybout and Westbrook (1995); Pavcnik (2002); Levinsohn and Petrin (forthcoming), and Aw, Chen and Roberts (2000). Tybout (2000) surveys this type of study for developing countries; Mairesse and Sassenou (1991) survey firm level studies that relate R\&D to productivity measures.

${ }^{3}$ On the input side, the typical data set reports the value of intermediate goods purchased, the historical cost of capital stocks, energy usage (sometimes in kilowatt hours, sometimes in value terms), and the number of workers or total hours worked, perhaps broken down by broad skill categories or gender. On the output side it describes sales revenue — sometimes distinguishing exports — and product classification according to standard industrial codes.
} 
expenditures. It also allows us to construct product-specific measures of consumer and producer surplus, and to relate these measures to policies, events, or managerial decisions.

Our last objective is to demonstrate our methodology on plant-level panel data from the Colombian manufacturing sector, and to compare our performance measures with standard measures (Section IV). We find, first, that standard performance measures are positively correlated with producer surplus because they depend positively upon mark-ups. (This is probably the reason that they are correlated with producers' survival rates and growth rates.) Second, these standard measures are not closely related to product quality measures and they are nearly orthogonal to consumer surplus measures, so from a social welfare standpoint, they are poor characterizations of producer performance. Third, firms with high marginal costs also tend to produce high quality products, so studies that presume homogenous products and view marginal production costs as an inverse index of performance tend to under-appreciate the producers of these goods. Finally, relating firms' performances to whether they engage in international trade, we find that standard measures imply trading firms tend to do worse, while our welfare-based measures suggest they do not.

\section{The Problem with standard performance measures}

To be specific about the features of $\widetilde{\phi}_{j t}$-type indices, let us assume that the production function may be written as:

$$
Q_{j t}=e^{\phi_{j t}} \cdot h\left(F_{j t}\right),
$$


where $Q_{j t}$ is the output of the $j^{\text {th }}$ plant in period $t, \phi_{j t}$ is its "true" productivity level, $h(\cdot)$ is a differentiable function, and $F_{j t}$ is a scalar index of factor usage. Also, let $F_{j t}$ be a constant returns function of the vector of inputs employed by the plant, $F_{j t}=f\left(\vec{V}_{j t}\right)$, where $\vec{V}_{j t}=\left\{V_{j t}^{1}, V_{j t}^{2}, \ldots, V_{j t}^{I}\right\}^{\prime}$ and factors that differ in quality enter $\vec{V}_{j t}$ as distinct inputs. ( $\vec{V}_{j t}$ collapses to a scalar in the case of labor productivity studies.)

When $Q_{j t}$ and $F_{j t}$ are observable and the function $h(\cdot)$ is known, the productivity index is retrievable as $\phi_{j t}=\ln Q_{j t}-\ln h\left(F_{j t}\right)$. But these conditions rarely prevail, so analysts usually proceed with imperfect information. Specifically, when data on physical output volumes are unavailable, they typically replace $Q_{j t}$ with $\widetilde{Q}_{j t}=R_{j t} / \bar{P}_{t}$, where $R_{j t}$ is the $j^{\text {th }}$ plant's nominal sales revenue and $\bar{P}_{t}$ is an industry-wide output price index. Similarly, if input quantities are unobservable, the convention is to replace them with a deflated measure of expenditure on inputs, $\widetilde{F}_{j t}=\left(\frac{B_{j t}}{\bar{B}_{t}}\right) F_{j t}$, where $\bar{B}_{t}$ is a sectorwide input price deflator and $B_{j t}$ is the price of a unit bundle of inputs for the $j^{\text {th }}$ plant. ${ }^{4}$ Thus performance is commonly measured by indices of the general form:

$$
\widetilde{\phi}_{j t}=\left(\ln R_{j t}-\ln \bar{P}_{t}\right)-\ln \hat{h}\left(\widetilde{F}_{j t}\right),
$$

\footnotetext{
${ }^{4}$ That is, $B_{j t}=\min _{V}\left[\sum_{i=1}^{I} W_{j t}^{i} V^{i} \mid 1=f(\vec{V})\right]$ where $\vec{W}_{j t}=\left\{W_{j t}^{i}, W_{j t}^{2}, \ldots, W_{j t}^{I}\right\}$ is the plant-specific vector of unit factor prices associated with the input vector $\vec{V}_{j t}$. If some elements of the input vector are measured in physical terms and others are measured in expenditure terms, the expression for $\widetilde{F}_{j t}$ is more complicated. We will treat this case in detail below.
} 
where $\hat{h}(\cdot)$ is an approximation to the function $h(\cdot)$.

Sales revenues depend upon demand conditions and the nature of competition, so we cannot describe the properties of $\widetilde{\phi}_{j t}$ without introducing additional assumptions about consumer and producer behavior. Suppose $N_{t}$ firms compete in the industry of interest during period $t$ and let demand for the $j^{\text {th }}$ firm's product be given by the differentiable function:

$$
Q_{j t}=m^{j}\left(\vec{P}_{t}, \vec{\omega}_{t}, Y_{t}\right), \quad j \in\left\{1, \cdots, N_{t}\right\}
$$

where $\vec{\omega}_{t}=\left\{\omega_{1 t}, \omega_{2 t}, \ldots, \omega_{N_{t} t}\right\}^{\prime}$ is a vector of product quality/appeal measures for all $N_{t}$ firms, $\vec{P}_{t}=\left\{P_{1 t}, P_{2 t}, \ldots, P_{N_{t} t}\right\}^{\prime}$ is the corresponding vector of product prices, and $Y_{t}$ is an index of total market size. ${ }^{5}$ Further, assume that current prices and product quality indices are common knowledge, $\vec{\omega}$ and $\vec{\phi}$ do not respond to the current or past output decisions of any producer, firms are price takers in factor markets, and they are pure Bertrand-Nash price setters in the product market.

\footnotetext{
${ }^{5}$ Define $_{m^{j}}{ }^{-1}\left(P_{j} \mid \vec{P}^{-j}, \vec{\omega}, Y\right)$ to be the inverse demand function for the $j^{\text {th }}$ firm, given the vector of prices for all other products, $\vec{P}^{-j}$, the complete vector of product qualities, and market size. Caplin and Nalebuff (1991) show that a pure Bertrand-Nash equilibrium exists if this function is convex and diminishing in $P_{j}$, so long as cost functions are convex. They also describe sufficient conditions on individual utility functions and the distribution of these utility functions across individuals for this property to obtain, and they demonstrate conditions for uniqueness. In particular, they show that the individual utility functions that underlie logit demand systems satisfy existence and uniqueness conditions. This type of demand system underlies our empirical work in the following sections.
} 
Under these assumptions, producer $j$ considers its marginal revenue product at input level $F_{j t}$ to be $\left(1-\frac{1}{\eta_{j t}}\right) \gamma_{j t} \frac{R_{j t}}{F_{j t}}$, where $\eta_{j t}=\frac{-\partial \ln m^{j}\left(\vec{P}_{t}, \vec{\omega}_{t}, Y_{t}\right)}{\partial \ln P_{j t}}$ is this firm's elasticity of demand and $\gamma_{j t}=\frac{d \ln h\left(F_{j t}\right)}{d \ln F_{j t}}$ is its returns to scale. Thus, equating the marginal revenue product of input bundles to their unit prices, producer by producer, we obtain a set of first-order conditions for equilibrium:

$$
R_{j t}=\left(\frac{\eta_{j t}}{\eta_{j t}-1}\right)\left(\frac{B_{j t}}{\gamma_{j t}}\right) F_{j t}, \quad j \in\left\{1, \cdots, N_{t}\right\}
$$

Finally, substituting (4) into (2), $\widetilde{\phi}_{j t}$ may be written as:

$$
\widetilde{\phi}_{j t}=\ln F_{j t}-\ln \hat{h}\left(\widetilde{F}_{j t}\right)+\ln \left(\frac{\eta_{j t}}{\eta_{j t}-1}\right)+\ln \left(\frac{B_{j t}}{\bar{P}_{t}}\right)-\ln \gamma_{j t}
$$

How well does $\widetilde{\phi}_{j t}$ capture performance? Changes in product quality or productive efficiency generally cause firms to adjust their size, so all of the terms on the right-hand side of (5) except $\ln \left(\frac{B_{j t}}{\bar{P}_{t}}\right)$ depend upon $\omega_{j t}$ and $\phi_{j t}$. But as we shall argue below, $\widetilde{\phi}_{j t}$ need not respond to variation in $\omega_{j t}$ and $\phi_{j t}$ in the way that is commonly presumed; that is, by taking on relatively high values when $\omega_{j t}$ and/or $\phi_{j t}$ are relatively large.

\section{A simple case}

To simplify our discussion of $\widetilde{\phi}_{j t}$, we shall assume that analysts are somehow able to correctly estimate the production function $h(\cdot)$ and the input aggregating function 
$f(\cdot){ }^{6}$ Further, in order to begin with a simple case, we shall momentarily suppose that factor usage can be precisely measured in physical terms $\left(\widetilde{F}_{j t}=F_{j t}\right)$, all firms face the same demand elasticity $\left(\eta_{j t}=\eta \quad \forall j, t\right)$, and all firms enjoy constant returns to scale $\left(\gamma_{j t}=1 \forall j, t\right.$ and $\left.d \ln h\left(F_{j t}\right)=d \ln F_{j t}\right)$.

Under these assumptions, $\ln F_{j t}-\ln \hat{h}\left(F_{j t}\right)$ drops out of equation 5 and $\ln \left(\frac{\eta_{j t}}{\eta_{j t}-1}\right)$ becomes a constant. So $\widetilde{\phi}_{j t}$ becomes proportional to real factor costs, and completely unrelated to productive efficiency or product quality. The former property obtains because firms burdened with high factor costs pass a fraction of them on to consumers as higher output prices, and therefore generate more revenue per unit input. The latter property obtains because, with $\eta$ and $\gamma$ parametrically fixed, shocks to $\phi_{j t}$ and $\omega_{j t}$ move $R_{j t}$ and $F_{j t}$ in equal proportion, leaving revenue per unit input unaffected (equation 4). ${ }^{7}$ (Klette and Raknerud, 2001, and Bernard et al, 2000, make similar observations in slightly different contexts.)

This dependence of $\widetilde{\phi}_{j t}$ on factor prices may subvert productivity analysis in a number of ways. For example, the common finding that small and new firms are relatively unproductive may partly reflect the fact that they pay relatively low wages and

\footnotetext{
${ }^{6}$ Estimation errors introduce another type of problem with $\widetilde{\phi}$-type measures, but they do not undo the ones we will focus upon here. Klette and Griliches (1996) provide discuss the estimation issues that arise when revenue-based output measures are used in place of volume indices.

${ }^{7}$ Shocks to efficiency and/or product quality can, however, affect the general level of $\widetilde{\phi}$ values if they affect the output price index, $\bar{P}_{t}$.
} 
provide few fringe benefits (Baily, et al 1992; Griliches and Ragev, 1996; Aw, Chen and Roberts, 2001). Similarly, productivity among exporters may tend to be understated if they enjoy duty drawback schemes that reduce the costs of their intermediate inputs. On the other hand, the finding that geographically clustered firms are relatively productive (Henderson, 2001), which is typically attributed to agglomeration economies, may simply reflect high wages and rental costs in urban areas. Likewise, the common tendency to find high $\widetilde{\phi}$ indices among R\&D-intensive firms (Mairesse and Sassenou, 1991) and among multinational firms (Blomstrom and Kokko, 1997; Aitken and Harrison, 1999) may trace partly to their high unit labor costs. ${ }^{8}$

Similar problems arise in time series. For example, in open economies, real exchange rate appreciation tends to drive up real wages in the tradeable goods industries. But it also tends to increase import penetration rates, so $\widetilde{\phi}$-type indices may falsely create the impression that import competition improves productivity among tradeable goods producers. Further, given that multinationals and exporters rely more intensively on imported intermediate goods (Kraay, et al, 2001), $\widetilde{\phi}$-type indices may falsely imply that they are relatively efficient during periods of real appreciation and heightened import competition. (We will return to this effect in section IV.D below.)

\section{Unobserved heterogeneity in factor stocks}

Thus far we have been assuming that each factor is homogeneous across plants, and we have been treating inputs with different characteristics-for example, different

\footnotetext{
${ }^{8}$ Here we are assuming that their productivity measure is constructed using an index of physical labor rather than a measure of expenditures on labor. We will consider the case of expenditure-based labor measures shortly.
} 
types of workers - as distinct elements of the $V$ vector. Data are never actually available in sufficient detail to do this, so it is natural to ask how the properties of $\widetilde{\phi}$ are affected by unobserved factor heterogeneity. The answer is that cross-plant and inter-temporal variation in factor prices will no longer be orthogonal to $\phi_{j t}$ and $\omega_{j t}$. Rather, assuming that factors are paid the value of their marginal product, one would expect to find positive correlation between $\widetilde{\phi}_{j t}$ and $\phi_{j t}$ or $\omega_{j t} .{ }^{9}$ But this source of variation in $\widetilde{\phi}_{j t}$ would simply reflect the fact that firms using high quality inputs get more and/or better output. It would reveal nothing about which firms are doing well in an economic sense, or whether firms are getting better over time.

\section{Endogenous demand elasticities}

Although the assumption of common demand elasticities is often invoked, it is unrealistic in many contexts. When some firms enjoy non-trivial market shares, formal characterizations of market equilibrium often imply that the larger firms face relatively low demand elasticities. ${ }^{10}$ Further, it is reasonable to expect that firms with high efficiency $\left(\phi_{j t}\right)$ and/or high quality products $\left(\omega_{j t}\right)$ will use relatively large bundles of

\footnotetext{
${ }^{9}$ This dependence of measured productivity on unobservable aspects of factor quality is well known (e.g., Griliches and Jorgenson, 1967).

${ }^{10}$ An inverse relationship between $\omega_{j t}$ or $\phi_{j t}$ and the perceived elasticity of demand arises in a variety of contexts. For example, in a Dixit-Stiglitz (CES) system, one can induce such a relationship by assuming $N$ is small. The nested logit demand system we adopt in sections III and IV also exhibits this property.
} 
factor inputs. ${ }^{11}$ Thus "good" (high $\phi$ and high $\omega$ ) firms may well enjoy relatively low demand elasticities and, accordingly, have relatively large $\widetilde{\phi}$ 's. To the extent that this linkage matters, $\widetilde{\phi}$ variation will not be entirely unrelated to performance.

However, elasticity effects are also likely to induce spurious variation in $\widetilde{\phi}$. For example, producers of close substitutes may look relatively inefficient because their demand is relatively elastic. Also, reductions in institutional barriers to entry may reduce the market power of incumbent firms (e.g., Pakes and McGuire, 1994), making them appear less productive. Similarly, when trade liberalization and exchange rate appreciation reduce the equilibrium prices of the largest domestic firms - which compete most directly with imports — these shocks will tend to reduce both the average $\widetilde{\phi}_{j t}$ value and dispersion in $\widetilde{\phi}_{j t}$, even if true productivity remains unaffected. ${ }^{12}$ This procompetitive effect of appreciation works against the real factor price effect mentioned earlier, which may help explain why the literature relating trade liberalization and import penetration rates to $\widetilde{\phi}_{j t}$-type measures reports mixed results (Tybout, 2001).

${ }^{11}$ For the case of a nested logit demand system, see Berry (1994). For a CES utility function,
$\left.U\left(\sum_{j}\left(e^{\omega_{j t}} Q_{j t}\right)^{\frac{\eta-1}{\eta}}\right]^{\frac{\eta}{\eta-1}}, Z\right)$, Melitz (2000) shows that with fixed $\gamma$ and a large number of products, market clearing implies: $\ln R_{j t}-\ln \bar{P}_{t} \approx\left(\frac{\eta-1}{\eta}\right) \gamma \cdot \ln F_{j t}+\left(\frac{1}{\eta}\right) \ln \left(\frac{R_{t}}{N_{t} \bar{P}_{t}}\right)+\left(\frac{\eta-1}{\eta}\right)\left(\phi_{j t}+\omega_{j t}\right) \cdot$ (Here $R_{t}$ is industry-wide revenues.) Substituting this expression into the first-order condition (4), one obtains a reduced-form expression for factor demand:

$\ln F_{j t}=\left[\frac{\eta}{\gamma+\eta \cdot(1-\gamma)}\right]\left\{\frac{1}{\eta} \ln \left(\frac{R_{t}}{\bar{P}_{t} N_{t}}\right)+\left(\frac{\eta-1}{\eta}\right)\left(\phi_{j t}+\omega_{j t}\right)+\gamma+\ln \left(\frac{\eta-1}{\eta}\right)-\ln \left(\frac{B_{j t}}{\bar{P}_{t}}\right)\right\}$, which implies $\operatorname{cov}[\ln F, \phi+\omega]>0$.

${ }^{12}$ This dispersion effect is one interpretation for the findings of Caves and Barton (1990). 


\section{Non-constant returns to scale}

Relaxing the assumption of constant returns introduces another possible source of co-variation between $\widetilde{\phi}$ and $(\phi, \omega)$. However, its sign is uncertain. Suppose returns to scale are above unity for the smallest firms but fall with size, as one would expect in most industries. Then positive shocks to $\phi_{j t}$ or $\omega_{j t}$ increase factor usage and reduce $\ln F_{j t}-\ln h\left(F_{j t}\right)$ until constant returns are reached. This negative effect of $\phi$ or $\omega$ on $\widetilde{\phi}$ will be somewhat moderated by the negative relationship between $\ln \gamma_{j t}$ and $F_{j t}$. So the scale effect is ambiguous unless returns to scale are the same at all firms sizes. ${ }^{13}$

Measuring some factor in expenditure terms

Thus far we have assumed that all factors are accurately measured in physical terms. But this is hardly realistic. With the possible exception of primary metals and some food processing sectors (e.g., dairy and grain mills), data on intermediate inputs for manufacturing plants are almost always expressed in expenditure terms. It is even more rare to find physical capital measured in terms of numbers of machines of each type and vintage. Therefore we now explore the properties of $\widetilde{\phi}$ when input expenditures are used as proxies for input usage.

Let some subset $E \subseteq\{1, \ldots, I\}$ of the inputs be measured in deflated expenditure terms, so that the measured input vector $\widetilde{\bar{V}}_{j t}$ has components $\widetilde{V}_{j t}^{i}=\left(\frac{W_{j t}^{i}}{{\overline{W_{t}}}^{i}}\right) V_{j t}^{i}$ for $i \in E$

\footnotetext{
${ }^{13}$ If there are decreasing returns to scale, expression (5) can be used to describe the limiting case of perfectly competitive product markets by letting $\eta$ approach infinity. (A unique pure Bertrand-Nash equilibrium does not exist in the limit if returns to scale are constant or increasing.) For the CES case described in footnote 11, it is easy to demonstrate that as $\eta \rightarrow \infty, \widetilde{\phi}_{j t} \rightarrow \phi_{j t}+\omega_{j t}$.
} 
and $\widetilde{V}_{j t}^{i}=V_{j t}^{i}$ for $i \notin E$. Further, let the input aggregator function be $F_{j t}=f\left(\vec{V}_{j t}\right)=\prod_{i=1}^{I}\left(V_{j t}^{i}\right)^{\mu_{i}}, \sum_{i} \mu_{i}=1$, and assume that returns to scale are $\gamma$ for all firms. Then $\ln h\left(\widetilde{F}_{j t}\right)=\gamma \ln f\left(\widetilde{\widetilde{V}}_{j t}\right)=\gamma\left[\ln F_{j t}+\sum_{i \in E} \mu_{i} \ln \left(\frac{W_{j t}^{i}}{{\overline{W_{t}^{i}}}^{i}}\right)\right]$, and $\widetilde{\phi}_{j t}$ can be written as:

$$
\begin{gathered}
\widetilde{\phi}_{j t}=\ln \left(\mu_{0}\right)+\ln \left(\frac{\eta}{\eta-1}\right)+\sum_{i \notin E} \mu_{i} \ln \left(\frac{W_{j t}^{i}}{\bar{P}_{t}}\right)+\gamma \sum_{i \in E} \mu_{i} \ln \left(\frac{\bar{W}_{t}^{i}}{\bar{P}_{t}}\right) \\
+(1-\gamma)\left(\sum_{i \in E} \mu_{i} \ln \left(\frac{W_{j t}^{i}}{\bar{P}_{t}}\right)+\ln F_{j t}\right)-\ln (\gamma) .
\end{gathered}
$$

All of the properties of (5) are still present in (6). But now the role of factor prices is more nuanced. In particular, when some factors are measured in expenditure terms, cross-plant variation in their prices no longer affects $\widetilde{\phi}_{j t}$ because these factor prices are excluded from the $\operatorname{sum} \sum_{i \notin E} \mu_{i}\left(\frac{W_{j t}^{i}}{\bar{P}_{t}}\right)$. On the other hand, by measuring some factors in expenditure terms, we introduce a new role for their deflators through the expression $\sum_{i \in E} \mu_{i}\left(\frac{\bar{W}_{t}^{i}}{\bar{P}_{t}}\right)$. Thus exchange rate fluctuations and other industry-wide factor price shocks still work their mischief temporally on performance measures, even if the price deflators are precisely constructed. Notice also that the cross-sectional effect of factor price variation is ambiguous under non-constant returns. It depends upon whether the factor in question is measured in expenditure terms, whether there are increasing or decreasing returns, and the strength of the negative effect of factor prices on input usage (see footnote 11). 
But don't we get sensible stories from $\widetilde{\phi}$ ?

To all of the above, one might object that $\widetilde{\phi}$-type performance measures nonetheless seem to "work." That is, many studies have found that firms with high $\widetilde{\phi}_{j t}$ values are more likely to be large or grow, and they are less likely to fail (Baily, Hulten and Campell, 1992; Olley and Pakes, 1996; Aw, Chen and Roberts, 2001; Baldwin and Gorecki, 1991; Lu and Tybout, 1996; Pavcnik, 2002). Does not this finding imply, as the authors of these studies suggest, that high- $\widetilde{\phi}_{j t}$ firms are more efficient and/or produce a relatively desirable product? It need not. Success ultimately depends upon profits rather than efficiency or product quality, and firms with low demand elasticities (i.e., large values of $\frac{\eta}{\eta-1}$ ) tend both to be profitable and to have high $\widetilde{\phi}_{j t}$ values, even if their productive efficiency and product quality are unexceptional.

To summarize, when analyzing differentiated product industries, it is a mistake to pretend that sales revenues and input expenditures measure physical outputs and inputs, respectively. This convention leads to spurious measures of productivity that may have little to do with efficiency or product quality yet tend to be correlated with policy shocks and managerial choices. Furthermore, even when efficiency and product quality are captured in some way, these performance measures do not tell us anything about firms' contributions to welfare. 


\section{An Alternative Approach to Measuring Performance}

How, then, is one to infer something about plants' performances when neither their physical output volumes $\left(Q_{j t}\right)$ nor their prices $\left(P_{j t},\right)$ are available? If the input vector $\left(\vec{V}_{j t}\right)$ is observable and demand elasticities are the same for all firms, Melitz (2000) suggests using the residuals from a revenue function to make inferences about $\phi_{j t}+\omega_{j t}$ (see footnote 11). But in most applications, important elements of the input vector are measured in expenditure terms, and/or it unrealistic to assume that the elasticity of demand is the same for large and small firms. Under these circumstances we propose using an alternative approach to inference.

Specifically, suppose total variable costs and total revenues, $\left(T \vec{C}_{t}, \vec{R}_{t}\right)=$ $\left[\begin{array}{cccc}T C_{1 t} & T C_{2 t} & T C_{N_{t} t} \\ R_{1 t} & R_{2 t} & & R_{N_{t} t}\end{array}\right]^{\prime}$, are observable for all plants and they reflect equilibrium in a differentiated product industry. Then, using the demand functions (3) and the first-order conditions for profit maximization (4), it may be possible to induce a unique mapping from $\left(T \vec{C}_{t}, \vec{R}_{t}\right)$ to $\left(\vec{P}_{t}, \vec{Q}_{t}, \vec{\omega}_{t}, \vec{C}_{t}\right)$, where $C_{j t}$ denotes the $j^{\text {th }}$ plant's marginal cost schedule in period $t$. Once such a mapping is established, one can use it to impute plantspecific consumer and producer welfare measures, to study the evolution of these welfare measures over time, and to relate them to policy shocks and managerial choices. ${ }^{14}$

\footnotetext{
${ }^{14}$ Without data on factor prices it is impossible to impute productivity measures, $\phi_{t}=\left\{\phi_{1 t}, \phi_{2 t}, \ldots, \phi_{N t}\right\}$, from observable variables. But these are relevant for welfare only inasmuch as they influence marginal costs, which are identified.
} 


\section{A. The demand system, producer behavior, and market equilibrium}

Several conditions must be satisfied in order to implement this strategy. First, one's assumptions concerning consumer and producer behavior must imply a unique set

of equilibrium prices and quantities $\left(\vec{P}_{t}, \vec{Q}_{t}\right)$ at each $\left(\vec{\omega}_{t}, \vec{C}_{t}\right)$, given observable control variables. (Sufficient conditions are described in Caplin and Nalebuff, 1991.) Second, given equilibrium output and marginal cost values, it must be possible to infer the associated total variable costs, $T C$ for each firm. Thus it is generally necessary to impose some structure on the marginal cost function.

These requirements rule out non-parametric approaches and some flexible functional forms, but it is not difficult to find a reasonable set of assumptions that suits our purposes. In the remainder of this paper we describe one approach to inference that seems to work well. First, we assume that marginal costs at the $j^{\text {th }}$ plant in year $t$ are given by the scalar $C_{j t}$, regardless of that plant's output level. (We do, however, allow $C_{j t}$ to evolve through time with plant-specific productivity and factor price shocks.) Second, we adopt Berry's (1994) representation of market equilibrium with nested logit demand functions. ${ }^{15}$

A brief review of Berry's (1994) model will serve to introduce parameters and their interpretation in the present context. At time $t$ let $j \in\left\{0,1, \ldots N_{t}\right\}$ index the $N_{t}+1$ available varieties, with $j=0$ corresponding to the "outside" variety. Further, assume that the product varieties can be grouped into $G+1<N_{t}+1$ nests. In our application the outside product will be a composite imported variety, and the remaining varieties will

\footnotetext{
${ }^{15}$ A simple logit demand system would also work; we use the nested logit for added generality.
} 
map one-to-one onto the set of active domestic plants. We will also define product nests according to the geographic region where the plants are located. For example, nest 1 includes the varieties of pulp and paper products manufactured in Bogota, nest 2 includes the varieties manufactured in Medellin or Cali, and so on.

Next, let the consumers active in period $t$ be indexed by $\ell \in\left(0, Y_{t}\right]$. Each period, each consumer in the market chooses a single unit of the variety that yields her the largest net indirect utility, where variety $j$ yields consumer $\ell$ net utility:

$$
u_{\ell j t}=\bar{u}_{j t}+\varsigma_{\ell g_{j} t}+(1-\sigma) \varepsilon_{\ell j t} .
$$

Here $g_{j} \in\{1, \cdots G\}$ denotes the index for the group (nest) that contains the $j^{\text {th }}$ variety, and $\bar{u}_{j t}$ is the cross-consumer mean utility delivered by good $j$. The last two terms on the right hand side of (5) are unobserved error components that capture individual taste differences among consumers. The first component, $\varsigma_{\ell g_{j} t}$, varies across nests but not within them, while $\varepsilon_{\ell j t}$ exhibits within-nest variation. Thus the parameter $0 \leq \sigma<1$ indexes the degree of substitutability among, versus within, the nests. ${ }^{16}$ Finally, $\varepsilon$ is distributed type- 1 extreme value across consumers, given $j$ and $t$, and $[\varsigma+(1-\sigma) \varepsilon]$ is distributed type-1 extreme value across consumers, given $t$. This implicitly defines the distribution $\varsigma$, which is itself a function of $\sigma$ (Cardell, 1997).

The mean utility delivered by domestic good $j$ in period $t$ depends on both its quality and price:

\footnotetext{
${ }^{16}$ As $\sigma$ goes to zero, within-group correlation of utilities goes to zero, and as $\sigma$ goes to unity, within-group correlation goes to unity. A more general specification lets $\sigma$ vary across groups, allowing richer substitution patterns (Berry, 1994; Berry, Levinsohn and Pakes, 1995). This specification has important advantages, but it requires that we observe information about the distinctive features of each group, which makes it infeasible for the present application.
} 


$$
\bar{u}_{j t}=\xi_{j t}-\alpha_{d} P_{j t}, \quad \forall j=1, \ldots, N
$$

where $\xi_{j t}$ measures product quality, $P_{j t}$ is the price, and $\alpha_{d}$ measures the price effect on the mean indirect utility of a given domestic good. Similarly, the mean indirect utility delivered by a unit of the composite imported good is:

$$
\bar{u}_{0 t}=\xi_{0 t}-\alpha_{f} \cdot P_{0 t},
$$

where $P_{0 t}$ is the domestic currency price of a unit of imports, calculated as the product of the tariff-inclusive real price of imports in U.S. dollars and the real effective peso-dollar exchange rate. Since the imported good is a composite, we allow $\alpha_{d}$ and $\alpha_{f}$ to differ.

Integrating over consumers yields a logit-based functional form for the $N_{t}$ demand functions (3), with arguments $Y_{t}, \vec{P}_{t}=\left(P_{0 t}, \vec{P}_{t}^{d}\right)$, and $\vec{\omega}_{t}=\left(0, \vec{\omega}_{t}^{d}\right)$, where $\vec{P}_{t}^{d}=\left\{P_{1 t}, P_{2 t}, \ldots, P_{N_{t} t}\right\}$ and $\vec{\omega}_{t}^{d}=\left\{\xi_{1 t}-\xi_{o t}, \xi_{2 t}-\xi_{o t}, \ldots, \xi_{N_{t} t}-\xi_{o t}\right\}$ (see appendix 1). Note that all domestic product qualities are measured relative to the quality of the imported good. Also, as Berry (1994) demonstrates, under the assumption of pure Bertrand-Nash pricing and flat marginal cost schedules, these demand functions imply a specific functional form for the $N_{t}$ profit maximizing conditions (4) (see appendix 1). Finally, the expressions:

$$
\begin{array}{ll}
R_{j t}=P_{j t} \cdot Q_{j t} & j \in\left\{1, \cdots, N_{t}\right\} \\
T C_{j t}=Q_{j t} \cdot C_{j t} & j \in\left\{1, \cdots, N_{t}\right\}
\end{array}
$$

provide $2 N_{t}$ additional restrictions. ${ }^{17}$

\footnotetext{
${ }^{17}$ More generally, one might assume that the cost function is common across plants up to a single unknown parameter that captures idiosyncratic efficiency and/or factor price effects.
} 
Suppose the demand parameters $\left(\alpha_{d}, \alpha_{f}, \sigma\right)$ are known and the data $\left(P_{0 t}, Y_{t}\right.$, $\vec{R}_{t}, T \vec{C}_{t}$ ) are available. Then the demand functions (3), the profit maximization conditions (4), the revenue expression (10) and the total variable cost expression (11) provide $4 \cdot N_{t}$ equations with which to identify the $4 \cdot N_{t}$ unknowns, $\left(\vec{Q}_{t}^{d}, \vec{P}_{t}^{d}, \vec{\omega}_{t}^{d}, \vec{C}_{t}\right)$. Similarly, if total market size $\left(Y_{t}=\sum_{j=0}^{N_{t}} Q_{j t}\right)$ is unobserved but the quantity of imports ( $\left.Q_{0 t}\right)$ is available, $\left(P_{0 t}, Q_{0 t}, \vec{R}_{t}, T \vec{C}_{t}\right)$ can used to solve for $\left(\vec{Q}_{t}^{d}, \vec{P}_{t}^{d}, \vec{\omega}_{t}^{d}, \vec{C}_{t}\right)$. Appendix 1 proves that a unique solution exists for the case of a nested logit and sketches an algorithm for finding it.

\section{B. The evolution of product quality and marginal costs}

It remains to link product quality and market costs to the business environment and managerial decisions. To this end we assume that product quality and the log of marginal costs evolve over time according to a vector autoregressive (VAR) process, conditioned on a vector $\boldsymbol{X}_{j t}$ of weakly exogenous variables, including things like R\&D expenditures, participation in foreign markets, and the extent of multinational ownership:

$$
\begin{gathered}
\omega_{j t}=\omega_{0}+\sum_{s=1}^{L} \lambda_{s} \omega_{j, t-s}+\sum_{s=L+1}^{2 L} \lambda_{s} \ln C_{j t+L-s}+\lambda^{x} \boldsymbol{X}_{j t}+\varepsilon_{j t}^{\omega}, \\
\ln C_{j t}=c_{0}+\sum_{s=1}^{L} \varphi_{s} \ln C_{j, t-s}+\sum_{s=L+1}^{2 L} \varphi_{s} \omega_{j, t+L-s}+\varphi^{x} \boldsymbol{X}_{j t}+\varepsilon_{j t}^{c}, \\
j=1, \cdots, N, \quad t=L+1, \cdots, T .
\end{gathered}
$$


Accordingly, once the complete vector of parameters has been estimated, it will be possible to trace the welfare effects of any deviation from observed $\boldsymbol{X}_{j t}$ trajectories. We shall assume that the errors $\left(\varepsilon^{\omega}, \varepsilon^{c}\right)$ are jointly normal and serially uncorrelated after controlling for plant effects.

\section{Estimation}

Without the VAR system described above, the demand parameters $\left(\alpha_{d}, \alpha_{f}, \sigma\right)$ are not identified. A different mapping from $\left(T \vec{C}_{t}, \vec{R}_{t}\right)$ to $\left(\vec{P}_{t}, \vec{Q}_{t}, \vec{\omega}_{t}, \vec{C}_{t}\right)$ exists for each feasible set of $\left(\alpha_{d}, \alpha_{f}, \sigma\right)$ values, and without more structure, each is equally likely. Equations (12a) and (12b) help with identification by constraining the shapes of the cross-sectional $\left(\vec{\omega}_{t}, \vec{C}_{t}\right)$ distributions and the way that individual $\left(\omega_{j t}, C_{j t}\right)$ pairs evolve through time. However, these constraints bear only obliquely on the demand parameters, and they introduce some new unknowns to be estimated. Prospects for successful maximum likelihood estimation are further dimmed by the irregular shape of the likelihood function for the nested logit (Lahiri andf Gao, 2001). Therefore we impose further structure by specifying priors on the unknown parameters and estimating the system (3), (4), (10), (11), (12) using Bayesian techniques.

To summarize this estimation strategy, let us collect all of the parameters we have introduced in the vector $\theta=\left[\alpha_{d}, \alpha_{f}, \sigma, \lambda, \varphi, \Sigma\right]$, where $\Sigma=E\left[\left(\begin{array}{c}\varepsilon_{c} \\ \varepsilon_{\omega}\end{array}\right)\left(\begin{array}{c}\varepsilon_{c} \\ \varepsilon_{\omega}\end{array}\right)\right]$, , and define the joint density $p(\theta)$ to describe our priors, which we will discuss shortly. Also, let us collect all of the observable data on revenues, costs, imports, the exchange rate, and 
weakly exogenous firm characteristics in the matrix $D$. Then the posterior distribution for $\theta$ is: $\pi(\theta \mid D)=\frac{p(\theta) \cdot L(D \mid \theta)}{\int_{\theta} p(\theta) \cdot L(D \mid \theta) d \theta} \propto p(\theta) \cdot L(D \mid \theta)$, where $L(D \mid \theta)$ is the likelihood function based on (3), (4), (10), (11), and (12).

Excepting elements of the covariance matrix, $\Sigma$, we have no reason to expect that the parameters of our model are correlated. Thus we write the joint prior distribution as a product of our prior marginal densities for the individual parameters:

$$
p(\theta)=p_{\sigma}(\sigma) \cdot p_{\alpha, \gamma}(\alpha, \gamma) \cdot p_{\varphi, \lambda}(\varphi, \lambda) \cdot p_{\Sigma}(\Sigma)
$$

Let us describe each component of $p(\theta)$ in turn. First, the demand system priors we impose are similar to those used by Poirier (1996) and Lahiri and Gao (2001). ${ }^{18}$ The underlying utility maximization problem implies that $\sigma \in[0,1]$, so we specify uniform priors on this region of support. ${ }^{19}$ Second, we believe the price coefficients $\alpha_{d}$ and $\alpha_{f}$ should be positive but we do not know much about their magnitudes, so we specify uniform priors with support $[0,10]$ for each of these parameters. The remaining parameters describe the VAR (equations 12a and 12b). For the autoregressive parameters we assume joint normality, $p_{\varphi, \lambda}(\varphi, \lambda)=N_{2 L}\left(0_{2 L}, 100 \times I_{2 L}\right)$, where $L$ is one plus the number of right-hand side variables appearing in each VAR equation. Finally, as is

\footnotetext{
${ }^{18}$ These studies also estimate nested logit models using Bayesian techniques. However, unlike ours, they are concerned with the problem of ill-defined nesting structures.

${ }^{19}$ Restricting $\sigma$ to be greater or equal to zero reflects our prior knowledge that the products within each nest are at least as good substitutes for each other as those products outside the nest. Values of $\sigma$ greater than one are not consistent with the underlying assumption of the extreme value distribution of consumer tastes. As $\sigma$ goes to unity, consumers would purchase only the goods with the highest mean indirect utility in each nest. Restricting $\sigma$ to be less than or equal to one ensures that all products get consumed.
} 
standard in the literature, for the covariance matrix we assume an inverted-Wishart

distribution, $p_{\Sigma}(\Sigma)=\operatorname{Inv} W i \operatorname{sh}\left(6,100 \times I_{2}\right)$. Overall then, with the exception of $\sigma$, we are doing little to constrain the range of plausible realizations on $\theta$.

Closed-form representations of the posterior $\pi(\theta \mid D)$ are not available; nor is it feasible to make i.i.d. draws directly from $\pi(\theta \mid D)$. We therefore use a Markov chain Monte Carlo (MCMC) algorithm to generate correlated draws from $\pi(\theta \mid D)$ and we analyze the moments of the resulting empirical distributions (Gilks, et al, 1996).

The vector $\theta$ is relatively large, so we exploit Gibbs sampling techniques to generate our Markov chain. That is, we partition $\theta$ into three sub-vectors:

$\theta=\left[\theta_{1}, \theta_{2}, \theta_{3}\right]$, where $\theta_{1}=\left(\alpha_{d}, \alpha_{f}, \sigma\right), \theta_{2}=(\lambda, \varphi)$ and $\theta_{3}=\Sigma$. Then we update the sub-vectors sequentially by drawing from the full conditional distributions of each in turn. The full conditional distribution of $\left(\theta_{2} \mid \theta_{1}, \theta_{3}, D\right)$ is multivariate normal because $D$ and $\theta_{1}$ imply the $(\omega, \ln C)$ trajectories, which contain all of the available information on $\theta_{2}$. For the same reason, the full conditional distribution of $\left(\theta_{3} \mid \theta_{1}, \theta_{2}, \mathrm{D}\right)$ is invertedWishart. Thus closed-form expressions for the full conditional distributions of $\theta_{2}$ and $\theta_{3}$ are easy to construct, and sampling from these distributions is straightforward (Zellner, 1971). However, no simple expression for the full conditional distribution of $\left(\theta_{1} \mid \theta_{2}, \theta_{3}\right.$, $D)$ is available, so we use a Metropolis-Hastings sampling algorithm. Appendix 2 provides further details.

\section{E. Constructing Performance Measures}

Once we have estimated our posterior distribution, $\pi(\theta \mid D)$, we solve for the marginal cost and product quality trajectories of each producer in the sample using the 
expected value of $\theta \cdot{ }^{20}$ The remaining task is then to translate these trajectories into meaningful performance measures, and to examine the relationship between those measures and the traditional Tornqvist indices described in Part I above.

For the $i^{\text {th }}$ producer, we calculate the increment to consumer surplus that it generates each period by evaluating consumer surplus with, versus without the $i^{\text {th }}$ good: ${ }^{21}$

$$
\left.\left.\Delta C S_{t}^{i}=y_{t} \cdot\left[\left[\sum_{j} \exp \left(\bar{u}_{j t} /(1-\sigma)\right)\right]^{(1-\sigma)}\right\}-\left[\sum_{j \neq i} \exp \left(\bar{u}_{j t} /(1-\sigma)\right)\right]^{(1-\sigma)}\right\}\right]
$$

Prices and market shares are allowed to adjust to re-establish equilibrium when good $m$ is removed. Similarly, we calculate the $i^{\text {th }}$ producer's own surplus as $\left(P_{i t}-C_{i t}\right) Q_{i t}$, and from this we subtract the negative externality this producer imposes on the surplus of other firms. The latter is imputed by evaluating $\sum_{j \neq i}\left(P_{j t}-C_{j t}\right) Q_{j t}$ with, versus without, the $i^{\text {th }}$ producer present, letting prices and market shares adjust to re-establish equilibrium.

To evaluate these firm-specific welfare contributions, we express them as ratios to firms' reported capital stock to obtain a crude social rate of return on investment. (All other costs of operation are captured by variable costs and will already be netted out of producer surplus.) Obviously we miss pre- and post-sample costs and benefits and our

\footnotetext{
${ }^{20}$ It would, of course, be possible to also study the distributions for these trajectories that are induced by $\pi(\theta \mid D)$; we have not pursued this yet.

${ }^{21}$ Ackerberg and Rysman (2001) argue that the nested logit demand system overstates the contribution to consumer surplus provided by each product because it implies very high marginal utility from the first units consumed of each good. Thus our results may over-emphasize consumer surplus relative to producer surplus.
} 
measure of firms' assets will be very crude, but we feel we will come closer to a comprehensive basis for assessment than the standard methodologies. For the sake of comparison, we also calculate the usual Tornqvist measures of total factor productivity under the standard assumptions that deflated revenues measure real output, and deflated expenditures on intermediate goods measure physical intermediate good usage:

$$
\widetilde{\phi}_{j t}=\ln \left(R_{j t} / \bar{P}_{t}\right)-\sum_{i=1}^{I} \hat{\mu}_{j t}^{i} \ln \left(\widetilde{V}_{j t}^{i}\right),
$$

where $\hat{\mu}_{j t}^{i}$ is the share of the $i^{\text {th }}$ factor in total costs at firm $j$ during period $t$.

\section{An Application to the Colombian Pulp and Paper Mill Industry}

\section{A. The Data}

We base our empirical example on panel data describing the Colombian pulp and paper mill industry over the period 1981-1991. These data were originally collected by Colombia's official statistical agency (Departmento Administrativo Nacional de Estadistica) and have been cleaned as described in Roberts (1996). To keep the analysis simple we exclude plants that entered or exited during the sample period, leaving a total of 13 plants over an 11 year period. ${ }^{22}$ This naturally creates some selection bias, although the entering and exiting plants were quite small and thus had a minor influence on market shares.

We construct total domestic sales, $R_{j t}$, as total sales revenue less the value of exports divided by a general wholesale price deflator. To construct total variable costs, $T C_{j t}$, we first sum payments to labor, intermediate input purchases net of inventory 
accumulation, and energy purchases. Then we scale this aggregate by the ratio of total domestic sales to total sales and we divide the result by the same wholesale price deflator we used for output. This definition of total variable cost implies, of course, that expenditures on physical capital are fixed costs. ${ }^{23}$

Our real exchange rate series, $e_{t}$, is taken from Ocampo and Villar (1995), who include an adjustment for tariffs. To impute imports we assume that all imported goods in the relevant industrial classification maintain their same exogenous dollar price during the sample period. Further, we assume that the imported varieties are consumed in fixed proportion to one another, so that they can be treated as a single bundle whose domestic price fluctuates only with the exchange rate. Then, calling the period $t$ dollar value of imports $R_{0 t}$, we construct our index of the quantity of imports as $Q_{0 t}=\frac{R_{0 t}}{P_{0 t}}$. The units in which $Q_{0 t}$ is measured determine the units in which all domestic varieties are measured and effectively fix the size of the market. ${ }^{24}$

Finally, the vector of weakly exogenous variables $\left(\boldsymbol{X}_{j t}\right)$ includes the book value of each plant's initial (1981) capital stock, a trend term, and two dummy variables that

\footnotetext{
${ }^{22}$ Entry and exit would complicate the VAR portion of the likelihood function by creating an unbalanced panel.

${ }^{23}$ An equally simple approach would be to assume that capital stocks are perfectly flexible, and to include a rental cost of capital - say 10 percent of the book value - in our total cost measure. The intermediate case in which capital stocks (and perhaps other inputs) are subject to finite adjustment costs is difficult to deal with because it means introducing dynamic optimization into the analysis.

${ }^{24}$ Unfortunately, the choice of the units of $Q_{0}$ also has implications concerning import volume shares. If we were to halve the imputed quantity of imports, the imputed volume share of imports would also be smaller. This reflects the fact that domestic quantities are not linear in $Q_{0}$. An increase in $Q_{0}$ does imply bigger domestic quantities but the increase is less than proportional. In practice, we normalize the series of real exchange rate so that in the base year revenue share of imports equals its volume share.
} 
summarize plants' participation in foreign markets. The first takes a value of one if the plant was importing some or all of its intermediate inputs in year $t-1$, but not exporting any of its output. The second dummy takes a value of one if the plant was both importing some intermediates and exporting some output in year $t-1$. No plant in our sample exported output without importing intermediate inputs, so the omitted category is simply plants that did not buy inputs or sell outputs in international markets in year $t-1 .{ }^{25}$

\section{B. Posterior Parameter Distributions}

Means, standard errors and other summary statistics for our estimated posterior distribution $\pi(\theta \mid D)$ are reported in Table 1 below. The estimates are constructed using Wooldrich's (2001) correction for persistent unobserved heterogeneity in the disturbance term. $^{26}$

Overall, the results appear quite well behaved, although the posterior distribution for the price coefficient $\alpha_{d}$ is rather diffuse. ${ }^{27}$ Given the small sample size we are working with, this is perhaps unsurprising. The mixing parameter $\sigma$ tends to be close to unity, suggesting that most of the variation in tastes across consumers has to do with region of origin. The VARs for product quality and marginal cost both show a plausible

\footnotetext{
${ }^{25}$ It would have been desirable to also include R\&D spending, and to distinguish firms according to whether they were partly owned by foreigners. Unfortunately, this information was not available.

${ }^{26}$ Wooldrich's (2001) correction takes care of initial conditions problem. It amounts to including the initial value of the lagged dependent variables as explanatory variables in all years, and using a standard error components specification for the disturbance. Kraay et al (2001) provide further discussion in the context of a similar VAR. Our results indicate that the variance of the random effect is sufficiently small to ignore, so we simply include initial values of the lagged dependent variables.

${ }^{27}$ The standard errors can be misleading because these are not symmetrically distributed random variables. For example, although a standard $t$-test would not reject the null hypothesis that $\alpha=0$, with 90 percent confidence, the 90 percent confidence intervals for $\sigma$ lie entirely in the positive domain.
} 
amount of persistence. On the other hand, there is less dynamic interaction among these variables than we expected. (That is, we thought high marginal cost in one year might lead to higher product quality in the next year.) Nonetheless, as we will see shortly, these variables do exhibit contemporaneous covariance across plants because of persistent plant effects. Finally, our coefficients for trends, international transactions, and capital stocks are not estimated with much accuracy. However, the impact of importing intermediate goods on marginal costs and product quality is large and negative, on average. We will return to explore the implications of these international transactions coefficients in section D below.

\section{Plant performance measures}

Using the posterior means of our demand parameters, we impute relative product qualities $\left(\omega_{j}\right)$, marginal costs $\left(C_{j}\right)$, contributions to consumer surplus over total

production costs, $\frac{\Delta U_{j}}{T C_{j}}$, producer surplus over value of the fixed capital stock, $\frac{\Pi_{j}}{K_{j}}$, external effects on the producer surplus of other plants over value of the fixed capital stock,$\frac{\Delta \sum_{k \neq j} \Pi_{k}}{K_{j}}$, and net total surplus created over fixed capital stocks, $\frac{\Delta U_{j}+\Pi_{j}}{K_{j}}+\frac{\Delta \sum_{k \neq j} \Pi_{k}}{K_{j}}$. Then pooling all 11 years of observations on the 13 plants in continuous operation, we obtain the descriptive statistics in table 2 . The results imply that the ratio of operating profits to fixed capital is roughly 7 percent, so the average rate of return on fixed capital investment is quite sensible. Domestic products are, on average, 
somewhat more attractive than the imported goods, but the cross-product standard deviation in relative appeal is substantial. (Robustness tests, not reported, show that it also depends on our $p_{\sigma}(\cdot)$ specification.) Most social surplus comes from the consumer side rather than the producer side (but see footnote 21 ). Indeed, the only reason that plants make a positive contribution to welfare is that this consumer surplus effect dominates the negative externality each plant imposes on the others by shrinking their market. (Some plants actually reduce net total welfare- this is a well known possibility in the case of monopolistic competition.)

We next calculated the cross-plant correlations in these variables reported in tables $3 .^{28}$ The implications are intriguing. First, relative product quality, $\omega_{j}$, and the $\log$ of marginal production costs, $\ln C_{j}$, are weakly correlated $(\rho=0.201)$. Thus on average, it costs relatively more to produce a relatively desirable good, and it is probably inappropriate to equate low production costs with superior performance.

Second, the standard total factor productivity measure $\left(\widetilde{\phi}_{j t}\right)$ is weakly associated with product quality $(\rho=0.238)$ because of the elasticity effect mentioned in sections II and III. So $\widetilde{\phi}_{j t}$ does partly capture an aspect of performance that is directly related to welfare $(\rho=0.435)$. On the other hand, $\widetilde{\phi}_{j t}$ is orthogonal to marginal costs $(\rho=0.022)$, which in turn reflects factor prices and technical efficiency. We cannot unbundled these two cost components without plant-specific information on factor prices, but if the

\footnotetext{
${ }^{28}$ We also looked at correlations of firms' rankings in terms of each of these variables. The results are nearly identical to those reported in Table 3 , so we do not report them here.
} 
dominant source of variation is technical efficiency, it follows that $\widetilde{\phi}_{j t}$ does a poor job of capturing $\phi_{j t}$.

Fourth, $\widetilde{\phi}_{j t}$ is fairly strongly associated with own-producer surplus, $\frac{\Pi_{j t}}{K_{j t}}$ $(\rho=0.600)$. This association with own surplus appears to reflect underlying variation in plant size. Specifically, low product quality not only reduces $\widetilde{\phi}_{j t}$, it dampens output and scales back $\Pi_{j t}=Q_{j t}\left(P_{j t}-C_{j t}\right)$.

Finally, although producer surplus is positively associated with $\widetilde{\phi}_{j t}$, the opposite is true of consumer surplus $(\rho=-0.153)$. Thus total surplus created over own fixed capital is only weakly related to $\widetilde{\phi}_{j t}(\rho=0.220)$. This correlation is the only one that matters if we are exclusively concerned with contributions to social welfare. Taken at face value, it implies that traditional Tornqvist indices — and, we suspect, the entire class of indices discussed in section II— tell us little about which firms are do well from a social perspective.

\section{Linking performance to policy}

It is popular to regress performance measures like $\widetilde{\phi}_{j t}$ on policy variables or plant characteristics that are considered to respond to policy. For example, variants of $\widetilde{\phi}_{j t}$ have often been regressed on measures of exposure to foreign technology, including foreign direct investment in the firm or its industry, and indicators for whether the firm is an 
exporter. As a final exercise, we demonstrate an alternative exercise using the welfarebased performance measures described in the previous section.

Specifically, we use the estimates in table 1 to quantify the effects of prohibiting firms from becoming exporters and/or importing intermediate goods. It would be straightforward to also prohibit consumers from importing foreign substitutes, but we will not do so in order to focus on these two production-side trade restrictions. Also, for the same reason, we will assume that total domestic demand evolves exactly as it would have in the absence of our policy shock, and that each producer draws the same VAR shocks $\left(\varepsilon_{j t}^{c}, \varepsilon_{j t}^{\omega}\right)$ that were actually observed.

Under these assumptions we can use our VAR parameters to calculate the paths for $\left(\omega_{j t}, \ln C_{j t}\right)$ that would have emerged if, beginning in 1982, all international producer trade had been shut down. The cross-plant temporal averages for these variables are graphed in Figure 1. As one could have predicted, since the use of imported intermediate imports reduces marginal costs (Table 1), our hypothetical policy regime results in marginal cost increases. It also results in slight quality increases as firms substitute toward domestic sources. The latter seems counter-intuitive, but it follows from our finding that high quality is weakly associated with high cost.

Substituting our parameter estimates and these counterfactual trajectories for $\left(\omega_{j t}, \ln C_{j t}\right)$ into equations (8), (9) and (12), we next re-solve for equilibrium each period and calculate the new trajectories for producer and consumer surplus. These are graphed in figure 2. On net, not much happens to producer surplus because prices and costs move in the same direction. (This helps explain why some producers use imported inputs and others do not.) More surprisingly, not much happens to consumer surplus 
either. The reason is that the higher prices of domestic varieties due to higher marginal costs are accompanied by slight increases in quality, and our demand system estimates imply that consumers care a great deal about quality. We caution that this result appears to depend upon our priors. Other priors led to posterior parameter distributions (not reported) that implied a 10 percent loss in consumer surplus when producers were prohibited from foreign trade.

A very different story would have emerged if we had relied on $\widetilde{\phi}_{j t}$-type measures for policy analysis. Fitting an AR(1) like those in table 1 to the Tornqvist index discussed earlier, we find that firms that imported their intermediate goods had significantly lower measured productivity. ${ }^{29}$ Thus cutting firms off from foreign trade would appear to significantly improve performance. This may reflect the fact that our sample period includes a major devaluation, which presumably encouraged exporting and the use of imported intermediate goods at the same time that it depressed $\widetilde{\phi}_{j t}$ through relative price effects (refer to equation 6). The top panel of figure 3 presents average trajectories of the performance measure $\widetilde{\phi}_{j t}$ with, versus without, producer trade.

It is noteworthy that the time series average value of this $\widetilde{\phi}$-type index tracks our welfare based index in figure 2 rather closely. Thus, in sense, the cross-producer variation in $\widetilde{\phi}$-type measures is much more problematic than temporal variation that is typical of the population of plants. However, the reason for the high temporal correlation between

\footnotetext{
${ }^{29}$ We regressed $\widetilde{\phi}_{j t}$ on $\widetilde{\phi}_{j t-1}$ and the same weakly exogenous variables that appear in the VAR specifications of table 1, making the same correction for unobserved heterogeneity. We obtained a coefficient of -0.163 (standard error 0.068 ) on our dummy for use of imported intermediates without exporting, and a coefficient of -0.220 (standard error 0.071 ) on our dummy for use of imported intermediates while simultaneously exporting.
} 
mean $\widetilde{\phi}_{j t}$ values and social welfare is that the market for pulp and paper products expands during the sample period, not that firms improved in terms of their marginal costs or product qualities (refer to Figure 1).

\section{Concluding Remarks}

The analysis we have presented here is crude in many ways. We have used a very simple demand system, we have assumed that marginal costs are flat with respect to output, we have ignored producers that were not present for the entire sample period, and we have ruled out any form of forward looking behavior — due either to dynamic pricing games or to capital accumulation. Finally, we have paid no attention to the institutional and technological features of the Colombian pulp and paper industry.

For all of these reasons, we do not wish to argue that the numbers we have presented here are the best that one can do. Rather, our objectives have been to argue that much of the literature on plant-level performance is fundamentally flawed, and to sketch an alternative approach to inference that we feel holds more promise. Significant refinements in most of the dimensions mentioned above are possible; we are optimistic that they will enhance the usefulness of our methodology. 


\section{Bibliography}

Ackerberg, Daniel and Mark Rysman (2002) "Unobserved Product Differentiation in Discrete Choice Models: Estimating Price Elasticities and Welfare Effects," NBER Working Paper No. 8798.

Aitken, Brian, and Ann Harrison (1999) "Do Domestic Firms Benefit from Foreign Direct Investment? Evidence from Panel Data," American Economic Review, pp. 605-618

Anderson, Simon, Andre de Palma and Jacques-Francois Thisse (1992) Discrete Choice Theory of Product Differentiation. Cambridge: MIT Press.

Aw, Bee-Yan, Xiaomin Chen, and Mark Roberts (2001) "Firm-Level Evidence on Productivity Differentials and Turnover in Taiwanese Manufacturing," Journal of Development Economics, pp. 51-86.

Bahk, Byong and Michael Gort (1993) "Decomposing Learning by Doing in New Plants," Journal of Political Economy, 101(4), pp. 561-583.

Baily, Martin, Charles Hulten and David Campbell (1992) "Productivity Dynamics in Manufacturing Plants," Brookings Papers on Economic Activity: Microeconomics, pp. 187-249.

Baldwin, John R. and Paul K. Gorecki (1991) "Entry, Exit, and Productivity Growth," in P. Geroski and J. Schwalbach, eds. Entry and Market Contestability: An International Comparison. Oxford and Cambridge: Blackwell, pp. 244-56.

Bernard, Andrew, Jonathan Eaton, J. Bradford Jensen and Samuel Kortum (2000) "Plants and Productivity in International Trade," NBER Working Paper 7688.

Berry, Steven. (1994) "Estimating Discrete-Choice Models of Product Differentiation," Rand Journal 25(2), pp. 242-262.

Berry, Steven, James Levinsohn and Ariel Pakes (1995) "Automobile Prices in Market Equilibrium,” Econometrica 63(4), pp. 841-890.

(1999) "Voluntary Export Restraints in Automobiles," American Economic Review 89(3), pp. 400-430.

Blomstrom, Magnus and Ari Kokko (1997). "How Foreign Investment Affects Host Countries,” World Bank PRD Working Paper No. WPS 1745.

Caplin, Andrew and Barry Nalebuff (1991) "Aggregation and Imperfect Competition: On the Existence of Equilibrium," Econometrica 59, pp. 25-60. 
Cardell, Scott (1997) "Variance Components Structures for the Extreme Value and Logistic Distributions with Application to Models of Heterogeneity," Econometric Theory 13, pp. 185-213.

Caves, Douglas, Lau Christiansen and W. Erwin Diewert (1982) “Output, Input and Productivity Using Superlative Index Numbers,” Economic Journal 92, pp. 73-96.

Caves, Richard and David Barton (1990) Efficiency in U.S. Manufacturing Industries. Cambridge: MIT Press.

Gilks, Walter R., Sylvia. Richardson and David J. Spiegelhalter (1996) "Introducing Markov Chain Monte Carlo," in Gilks, W. R., S. Richardson and D. J. Spiegelhalter, eds., Markov Chain Monte Carlo in Practice. London: Chapman and Hall/CRC.

Griliches, Zvi. (1986). "Productivity, R\&D and Basic Research at the Firm Level in the 19870s," American Economic Review 76(1), pp. 141-154.

Griliches, Zvi and Haim Ragev (1995) "Firm Productivity in Israeli Industry: 19791988," Journal of Econometrics, 65(1), pp.175-203.

Henderson, Vernon (2001) "Marshall's Scale Economies," processed, Department of Economics, Brown University.

Jorgenson, Dale and Zvi Griliches (1967). "The Explanation of Productivity Change," Review of Economic Studies 34(3), pp. 249-83.

Klette, Tor and Zvi Griliches (1996) "The Inconsistency of Common Scale Estimators When Output Prices Are Unobserved and Endogenous," Journal of Applied Econometrics, 11(4), pp. 343-61.

Klette, Tor and Arvid Raknerud (2001) "How and Why do Firms Differ?” processed, Department of Economics, University of Oslo.

Kraay, Aart, Isidro Soloaga and James Tybout (2001) "Product Quality, Productive Efficiency, and International Technology Diffusion: Evidence from Plant-Level Panel Data," World Bank Policy Research Working Paper No. 2759.

Lahiri, Kajal and Jian Gao (2001) "Bayesian Analysis of Nested Logit Model by Markov Chain Monte Carlo," processed, Department of Economics, University at Albany-SUNY.

Levinsohn, James and Amil Petrin (forthcoming) "Estimating Production Functions using Inputs to Control for Unobservables," Review of Economic Studies. 
Liu, Lili and Tybout, James (1996) "Productivity Growth in Chile and Colombia: The Role of Entry, Exit and Learning," in Mark Roberts and James Tybout, eds., Industrial Evolution in Developing Countries. Oxford: Oxford University Press.

Marshak, J. and W. H. Andrews (1944). "Random Simultaneous Equations and the Theory of Production," Econometrica, 50, pp. 649-670.

Mairesse, Jacques and Mohamed Sassenou (1991). "R\&D and Productivity: A Survey of Econometric Studies at the Firm Level." STI Review (OECD, Paris), 1991, pp. 943.

McFadden, Daniel (1974) "Conditional Logit Analysis of Qualitative Choice Behavior," in Paul Zarembka, ed., Frontiers in Econometrics. New York: Academic Press, 1974.

Melitz, Marc (2000) "Estimating Productivity in Differentiated Product Industries," Department of Economics, Harvard University.

Ocampo, Jose Antonio and Leonardo Villar (1995) "Colombian Manufactured Exportes, 1967-91," in Gerald Helleiner, editor, Manufacturing for Export in the Developing World: Problems and Possibilities. New York, N.Y.: Routledge.

Olley, Steven and Ariel Pakes (1996) "The Dynamics of Productivity in the Telecommunications Equipment Industry," Econometrica, 64(6), pp. 1263-1297.

Pakes, Ariel and Paul McGuire (1994). "Computing Markov-Perfect Nash Equilibria: Numerical Implications of a Dynamic Differentiated Product Model," RAND Journal of Economics, 25(4), pp. 555-589.

Pavcnik, Nina (2002) "Trade Liberalization, Exit, and Productivity Improvements: Evidence from Chilean Plants," The Review of Economic Studies 69: 245-276.

Poirier, Dale (1996) “A Bayesian Analysis of Nested Logit Models,” Journal of Econometrics 75, pp. 163-181.

Roberts, Mark (1996) "Colombia, 1977-85: Producer Turnover, Margins, and Trade Exposure," in Mark Roberts and James Tybout, editors, Industrial Evolution in Developing Countries. New York: Oxford University Press.

Tybout, James (2000) "Manufacturing Firms in Developing Countries: How Well do They do, and Why?" Journal of Economic literature 38(1), pp. 11-44.

(forthcoming) "Plant- and Firm-Level Evidence on the 'New' Trade Theories," in James Harrigan (ed.) Handbook of International Trade, Oxford: Basil-Blackwell. 
Tybout, James, Jaime de Melo and Vittorio Corbo (1991) "The Effects of Trade Reforms on Scale and Technical Efficiency: New Evidence from Chile," Journal of International Economics 31, pp. 231-250.

Tybout, James and M. Daniel Westbrook (1995). "Trade Liberalization and Dimensions of Efficiency Change in Mexican Manufacturing Industries," Journal of International Economics 39, pp. 53-78.

Wooldridge, Jeffrey (2000) "The Initial Conditions Problem in Dynamic, Nonlinear Panel Data Models with Unobserved Heterogeneity," unpublished working paper, Department of Economics, Michigan State University.

Zellner, Arnold (1971) An Introduction to Bayesian Inference in Econometrics. New York: Wiley. 


\section{Appendix 1: Inferring Qualities and Quantities from Revenues and Costs}

This appendix demonstrates that a unique mapping exists from $\left(P_{0 t}, Q_{0 t}, T \vec{C}_{t}, \vec{R}_{t}\right)$ to $\left(\vec{P}_{t}, \vec{Q}_{t}, \vec{\omega}_{t}, \vec{C}_{t}\right)$ and sketches an algorithm for finding it. The mapping is done period by period, so we shall hereafter drop $t$ subscripts to reduce clutter.

First, let us replicate some well-known expressions for nested logit demand systems. Under the assumptions reviewed in section IIa, demand for the $j^{\text {th }}$ domestic variety, expressed as share of total demand for varieties in the $j^{\text {th }}$ product's nest (region), is:

$$
S_{j \mid g_{j}}=\frac{\exp \left[\left(\omega_{j}-\alpha_{d} P_{j}+\alpha_{f} P_{0}\right) /(1-\sigma)\right]}{\sum_{k \ni g_{k}=g_{j}} \exp \left[\left(\omega_{k}-\alpha_{d} P_{k}+\alpha_{f} P_{0}\right) /(1-\sigma)\right]}
$$

Also, expressed as a share of total demand for the industry's product, demand for the products in the $j^{\text {th }}$ product's nest as is:

$$
S_{g_{j}, t}=\frac{\left\{\sum_{k \ni g_{k}=g_{j}} \exp \left[\left(\omega_{k}-\alpha_{d} P_{k}+\alpha_{f} P_{0}\right) /(1-\sigma)\right]\right\}^{(1-\sigma)}}{\sum_{m=1}^{G}\left\{\sum_{k \ni g_{k}=m} \exp \left[\left(\omega_{k}-\alpha_{d} P_{k}+\alpha_{f} P_{0}\right) /(1-\sigma)\right]\right\}^{(1-\sigma)}+1} .
$$

Therefore our functional form for the $j^{\text {th }}$ producer's demand function (equation 3 ) is $m^{j}(\vec{P}, \vec{\omega}, Y \mid \theta)=s_{j \mid g} \cdot s_{g} \cdot Y$, and profits for the $j^{\text {th }}$ producer may be written as: $\Pi_{j}=\left(P_{j}-C_{j}\right) \cdot S_{j \mid g_{j}} \cdot S_{g_{j}} \cdot Y$. Further, given pure Bertrand-Nash pricing strategies, the standard first order conditions for profit maximization imply that equation (4) may be written as (Berry, 1994): 


$$
P_{j}=C_{j t}+\frac{(1-\sigma) / \alpha_{d}}{1-\sigma \cdot S_{j \mid g_{j}}-(1-\sigma) \cdot S_{j \mid g_{j}} \cdot S_{g_{j}}}, \quad j=1, \ldots N
$$

Our objective is to show that, given $\left(P_{0}, Q_{0}, T \vec{C}, \vec{R}\right)$, the $4 \cdot N$ unknowns $(\vec{P}, \vec{Q}, \vec{\omega}, \vec{C})$ are uniquely determined by (A1.1) through (A1.3) and (10) and (11) of the text.

First, by equation (11), total variable costs at the $j^{\text {th }}$ plant are $T C_{j}=Q_{j} C_{j}$, so the within-group market share of the $j^{\text {th }}$ firm is: $S_{j \mid g_{j}}=\frac{T C_{j}}{C_{j}} / Q_{g_{j}}^{\text {tot }}$ where total output from the $j^{\text {th }}$ plant's group is $Q_{g_{j}}^{t o t}=\sum_{k \ni g_{k}=g_{j}} \frac{T C_{k}}{C_{k}}$ and total domestic output is $Q^{t o t}=\sum_{g=1, G} Q_{g}^{t o t}$. Also, by equation (10), total revenues at the $j^{\text {th }}$ plant are $R_{j}=P_{j} Q_{j}$, so the $j^{\text {th }}$ plant's price-cost markup may be expressed in terms of observable variables as $m_{j}=\frac{R_{j}}{T C_{j}}-1$, and once its marginal cost is known, its price can be calculated as $P_{j}=\left(m_{j}+1\right) C_{j}$.

Substituting these market share and price expressions into the pricing rule (A1.3) and solving for marginal cost, we obtain:

$$
C_{j}=\sigma \cdot\left(\frac{T C_{j}}{Q_{g_{j}}^{t o t}}\right)+(1-\sigma) \cdot\left(\frac{T C_{j}}{Q^{t o t}+Q_{0}}+\frac{1}{\alpha \cdot m_{j}}\right) .
$$

This expression defines the unobservable $C_{j}$ as a monotonic decreasing function of $Q_{g_{j}}^{t o t}$, given data on $T C_{j}, m_{j}, Q^{t o t}$ and $Q_{0}$. Thus, once the nest quantity subtotals are 
known, each firm's marginal costs are implied by (A1.1). With these marginal costs, prices can be retrieved from $P_{j}=\left(m_{j}+1\right) C_{j}$. In turn, these imply quantities $Q_{j}=R_{j} / P_{j}$, and market shares follow trivially. Finally, once prices and market shares are known, the vector of product qualities can be found by substituting into:

$$
\omega_{j} \equiv \xi_{j}-\xi_{0}=\alpha_{d} P_{j}-\alpha_{f} P_{0}-\sigma \ln \left(S_{j \mid g_{j}}\right)+\ln \left(S_{j \mid g_{j}} \cdot S_{g_{j}}\right)-\ln \left(S_{0}\right),
$$

which follows from (A1.1) and (A1.2). ${ }^{30}$ (Here $S_{0}=1-\sum_{g=1}^{G} S_{g}$ is the market share of the imported variety.)

To solve for the nest quantity subtotals, note that $Q_{g_{j}}^{t o t}=\sum_{k \ni g_{k}=g_{j}} \frac{T C_{k}}{C_{k}}$.

Substituting the marginal cost expression (A1.5) into this sum, and dividing both sides by $Q_{g_{j}}^{\text {tot }}$, one obtains:

$$
\begin{array}{r}
1=\sum_{k \ni g_{k}=g}\left[\frac{1}{\sigma+(1-\sigma) \cdot Q_{g}^{t o t} \cdot\left(\left(Q^{t o t}+Q_{0}\right)^{-1}+\left(\alpha \cdot T C_{k} \cdot m_{k}\right)^{-1}\right)}\right], \\
g=1, \ldots G .
\end{array}
$$

The right-hand side of (A1.6) is a monotonic negative function of $Q_{g}^{\text {tot }}$ with value $n_{g} \sigma^{-1}>1$ at $Q_{g}^{\text {tot }}=0$ and limit 0 as $Q_{g}^{\text {tot }} \rightarrow \infty$, where $n_{g}$ is the number of producers

\footnotetext{
${ }^{30}$ Berry, Levinsohn and Pakes (1995) use a similar inversion to study the quality of automobile models.
} 
in nest $g$. Thus, for all $g \in\{1, \ldots G\}, Q_{0}>0$, and $Q^{\text {tot }} \geq 0$, equation (A1.7) has a unique, positive root: $Q_{g}^{\text {tot }}=f_{g}\left(Q^{t o t} \mid Q^{0}\right)$, which can be found using a bisection algorithm at any $Q^{t o t}$.

Finally, we will show that $Q^{t o t}-\sum_{g=1, G} f_{g}\left(Q^{t o t} \mid Q_{0}\right)=0$ has a unique positive root for any given $Q_{0}>0$. The existence of at least one root follows from the fact that

$$
\begin{gathered}
\sum_{g=1, G} f_{g}\left(Q^{\text {tot }} \mid Q_{0}\right) \text { is continuous in } Q^{\text {tot }}, Q^{\text {tot }} \rightarrow 0\left[Q^{\text {tot }}-\sum_{g=1, G} f_{g}\left(Q^{\text {tot }} \mid Q_{0}\right)\right]<0 \text { and } \\
\lim _{Q^{\text {tot }} \rightarrow \infty}\left[Q^{\text {tot }}-\sum_{g=1, G} f_{g}\left(Q^{\text {tot }} \mid Q_{0}\right)\right]>0 \text {. Uniqueness follows from the fact that: } \\
\frac{Q^{t o t}}{Q^{t o t}+Q^{0}}=\sum_{g=1, G} \frac{f_{g}\left(Q^{t o t} \mid Q^{0}\right)}{Q^{t o t}+Q^{0}}=\sum_{g=1, G} s_{g}\left(Q^{t o t} \mid Q^{0}\right)
\end{gathered}
$$

is a continuous decreasing function of $Q^{\text {tot }}$. This can be seen by restating (A1.2) as:

$1=\sum_{k \ni g_{k}=g}\left[\frac{1}{\sigma+(1-\sigma) \cdot s_{g} \cdot\left(1+\left(Q^{t o t}+Q_{0}\right)\left(\alpha \cdot T C_{k} \cdot m_{k}\right)^{-1}\right)}\right], g=1, \ldots G$, which implies that $s_{g}$ falls with $Q^{t o t}, g=1, \ldots G$. Again, a bracketing and bisection algorithm suffices to generate numerical solutions. 


\section{Appendix 2: The Gibbs Sampler}

Because it is not feasible to sample independent draws from the density $\pi(\theta \mid D)$ $\propto p(\theta) \cdot L(D \mid \theta)$, we use Markov chain Monte Carlo (MCMC) techniques. The idea is to draw a sequence of realizations on $\theta$ from some Markov process, $\left\{\theta^{(1)}, \theta^{(2)}, \cdots, \theta^{(i)}\right\}$, with elements whose unconditional distributions converge to $\pi(\theta \mid D)$ as $i \rightarrow \infty$. After discarding the early draws to eliminate the effects of the starting values, one can approximate the posterior moments of $\theta$ by constructing their sample counterparts from the chain.

The mostly commonly used MCMC algorithm is the Gibbs sampler. It generates a Markov chain by breaking the parameter vector into sub-vectors with full conditional distributions that can be sampled from, then using these conditional distributions to update the sub-vectors sequentially (Gilks, et al, 1996). We exploit Gibbs sampling techniques by breaking $\theta$ into 3 sub-vectors: $\theta_{1}=\left(\alpha_{d}, \alpha_{f}, \sigma\right), \theta_{2}=(\lambda, \phi)$, and $\theta_{3}=\operatorname{vec}(\Sigma)$. These we update according to the following algorithm:

Step 0: Set the initial values $\theta^{(0)}=\left(\theta_{1}^{(0)}, \theta_{2}^{(0)}, \theta_{3}^{(0)}\right)$, and $i=0$.

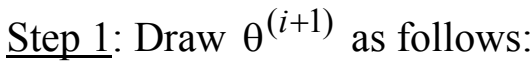
a) $\operatorname{Draw} \theta_{1}^{(i+1)} \sim \pi_{1}\left(\theta_{1} \mid \theta_{2}^{(i)}, \theta_{3}^{(i)}, D\right)$
b) $\operatorname{Draw} \theta_{2}^{(i+1)} \sim \pi_{2}\left(\theta_{2} \mid \theta_{1}^{(i+1)}, \theta_{3}^{(i)}, D\right)$
c) $\operatorname{Draw} \theta_{3}^{(i+1)} \sim \pi_{3}\left(\theta_{3} \mid \theta_{1}^{(i+1)}, \theta_{2}^{(i+1)}, D\right)$

Step 2: Set $i=i+1$, and go to step 1 . 
The distribution $\pi_{1}\left(\theta_{1} \mid \theta_{2}, \theta_{3}, D\right)$ is the most difficult to construct. It is proportional to $L\left(D \mid \theta_{1}, \theta_{2}, \theta_{3}\right) p_{\theta_{1}}\left(\theta_{1}\right)$ where $L\left(D \mid \theta_{1}, \theta_{2}, \theta_{3}\right)$ is the likelihood function based on (10)-(12) and (A1.1)-(A1.3); and $p_{\theta_{1}}\left(\theta_{1}\right)$ is the prior distribution defined in the text. But $L\left(D \mid \theta_{1}, \theta_{2}, \theta_{3}\right) f_{\theta_{1}}\left(\theta_{1}\right)$ does not have a closed form expression, so we draw $\theta_{1}$ using the random-walk Metropolis algorithm with a normal proposal density. The performance of the random-walk Metropolis algorithm depends crucially on the variance -covariance matrix of the proposal density. If the variance-covariance matrix is too big, then nearly all proposed moves will be accepted (high acceptance) but the random walk will move around the parameter space very slowly (slow mixing). On the other hand, if the variance-covariance matrix is too small, then an excessively large fraction of proposed moves will be rejected (low acceptance), although those draws that are accepted will move the chain by large increments. To balance these two effects, the convention is to choose the variance-covariance matrix in such a way that the empirical overall acceptance rate is around between 0.15 and 0.5. For more details, see Gilks, et al, (1996, chapter 7). We experimented until this condition was satisfied.

To describe $\pi_{2}\left(\theta_{2} \mid \theta_{1}, \theta_{3}, D\right)$ and $\pi_{3}\left(\theta_{3} \mid \theta_{1}, \theta_{2}, D\right)$, let us rewrite (13a) and (13b) as $Y_{j t}=\beta^{\prime} Z_{j t}+\varepsilon_{j t}$ where $Y_{j t}=\left(\omega_{j t}, c_{j t}\right)^{\prime}, Z_{j t}=\left(1, \omega_{j t-1}, c_{j t-1}, X_{j t}^{\prime}\right)^{\prime}$, $\varepsilon_{j t}=\left(\varepsilon_{j t}^{\omega}, \varepsilon_{j t}^{c}\right)$, and $\beta^{\prime}=\left(\begin{array}{cccc}\omega_{0} & \lambda_{\omega} & \lambda_{C} & \lambda_{X}^{\prime} \\ c_{0} & \phi_{\omega} & \phi_{C} & \phi_{X}^{\prime}\end{array}\right)$. Also, stacking observations, let us define: 


$$
\begin{aligned}
& Y=\left[\begin{array}{llllllll}
Y_{12} & \cdots & Y_{1 T} & \cdots & \cdots & Y_{N 2} & \cdots & Y_{N T}
\end{array}\right]^{\prime}, \\
& X=\left[\begin{array}{llllllll}
X_{12}^{\prime} & \cdots & X_{1 T}^{\prime} & \cdots & \cdots & X_{N 2}^{\prime} & \cdots & X_{N T}^{\prime}
\end{array}\right]^{\prime} \\
& Z=\left[\begin{array}{llllllll}
Z_{12} & \cdots & Z_{1 T} & \cdots & \cdots & Z_{N 2} & \cdots & Z_{N T}
\end{array}\right]^{\prime}, \\
& U=\left[\begin{array}{llllllll}
U_{12} & \cdots & U_{1 T} & \cdots & \cdots & U_{N 2} & \cdots & U_{N T}
\end{array}\right]^{\prime}
\end{aligned}
$$

Then, we can write the VAR system as $Y=Z \beta+U$. Further, conditional on $\theta_{1}$, our oneto-one mapping from $\left(T \vec{C}_{t}, \vec{R}_{t} \mid Q_{0 t}, P_{0 t}\right)$ to $\left(\vec{\omega}_{t}, \vec{C}_{t}\right)$ allows us to infer $(Y, Z)$ from $\left(\theta_{1}, D\right)$. Thus the construction of $\pi_{2}\left(\theta_{2} \mid \theta_{1}, \theta_{3}, D\right)$ and $\pi_{3}\left(\theta_{3} \mid \theta_{1}, \theta_{2}, D\right)$ is a standard exercise (Zellner, 1971).

Specifically, the likelihood-based full conditional distribution of $\theta_{2}$, given $\left(\theta_{1}, \theta_{3}, D\right)$, is normal with mean $\left(\left(Z^{\prime} Z\right)^{-1} Z^{\prime} \otimes I_{2}\right) \cdot \operatorname{vec}\left(Y^{\prime}\right)$ and variance $\left(Z^{\prime} Z\right)^{-1} \otimes \Sigma$. The full conditional posterior distribution for $\theta_{2}$ efficiently blends this information with our priors. We have assumed that $\theta_{2}$ has prior distribution $N\left(u_{0}, V_{0}\right)$, so $\pi_{2}\left(\theta_{2} \mid \theta_{1}, \theta_{3}, D\right)$ is multivariate normal with mean $u_{n}=V_{n}\left(\left[Z^{\prime} \otimes \Sigma^{-1}\right) \operatorname{vec}\left(Y^{\prime}\right)+V_{0}^{-1} u_{0}\right\rfloor$ and variance $V_{n}=\left[\left(\left(Z^{\prime} Z\right) \otimes \Sigma^{-1}\right)+V_{0}^{-1}\right]^{-1}$.

Similarly, using the mapping $\left(\theta_{1}, \theta_{2}, D\right) \rightarrow(\beta, Y, Z)$, we may write the likelihoodbased full conditional estimator of $\Sigma$, given $\left(\theta_{1}, \theta_{2}, D\right)$, as $\frac{1}{N(T-1)} \sum_{i=1}^{N} \sum_{t=2}^{T}\left(Y_{i t}-Z_{i t} \beta\right)\left(Y_{i t}-Z_{i t} \beta\right)^{\prime}$. When multiplied by $N(T-1)$, this estimator has a Wishart distribution with $N(T-1)$ degrees of freedom. Thus, given that we have assumed $\Sigma$ has prior distribution $\operatorname{Inv} \operatorname{Wish}\left(m_{0}, G_{0}^{-1}\right)$, the full conditional posterior distribution for 
$\theta_{3}=\operatorname{vec}(\Sigma)$, i.e., $\pi_{3}\left(\theta_{3} \mid \theta_{1}, \theta_{2}, D\right)$, is the vector version of a $\operatorname{Inv} \operatorname{Wish}\left(m_{n}, G_{n}^{-1}\right)$

distribution, where $m_{n}=m_{0}+N(T-1)$ and $G_{n}^{-1}=G_{0}^{-1}+(Y-Z \beta)^{\prime}(Y-Z \beta)$. 
TAble 1: Posterior Parameter Distributions

\begin{tabular}{|c|c|c|c|c|c|c|}
\hline & Mean & $\begin{array}{l}\text { Std. } \\
\text { Error }\end{array}$ & Median & Skewness & $5 \%$ & $95 \%$ \\
\hline & \multicolumn{6}{|c|}{ Demand System } \\
\hline$\overline{\alpha_{d} \text { (prior: } \alpha \sim U[0,10] \text { ) }}$ & 4.194 & 2.845 & 3.696 & 0.375 & 0.437 & 9.198 \\
\hline$\alpha_{f}$ (prior: $\gamma \sim U[0,10]$ ) & 1.086 & 0.779 & 0.997 & 0.463 & 0.070 & 2.423 \\
\hline \multirow[t]{2}{*}{$\sigma$ (prior: $\sigma \sim U[0,1]$ ) } & 0.970 & 0.023 & 0.975 & -1.029 & 0.927 & 0.997 \\
\hline & \multicolumn{6}{|c|}{ Product Quality VAR } \\
\hline$\lambda_{1}$ (constant) & -0.436 & 3.186 & -0.229 & -0.199 & -5.876 & 4.608 \\
\hline$\lambda_{2}\left(\omega_{i t-1}\right)$ & 0.469 & 0.376 & 0.468 & 0.008 & -0.152 & 1.086 \\
\hline$\lambda_{3}\left(\ln C_{i t-1}\right)$ & 0.053 & 0.237 & 0.056 & -0.032 & -0.343 & 0.437 \\
\hline$\lambda_{4}($ trend $)$ & -0.021 & 0.046 & -0.020 & -0.219 & -0.098 & 0.052 \\
\hline$\lambda_{5}$ (initial capital stock) & -0.009 & 0.101 & -0.007 & -0.133 & -0.179 & 0.153 \\
\hline$\lambda_{6}($ exported, $\mathrm{t}-1)$ & 0.029 & 0.374 & 0.022 & 0.059 & -0.578 & 0.648 \\
\hline$\lambda_{7}$ (imported intermediates, $\mathrm{t}-1$ ) & -0.040 & 0.385 & -0.041 & 0.030 & -0.679 & 0.595 \\
\hline$\vartheta_{1}^{\omega}\left(\omega_{i 1}\right)$ & 0.788 & 1.373 & 0.781 & 0.051 & -1.467 & 3.051 \\
\hline \multirow[t]{2}{*}{$\vartheta_{2}^{\omega}\left(\ln C_{i 1}\right)$} & -0.192 & 0.382 & -0.157 & -0.511 & -0.897 & 0.353 \\
\hline & \multicolumn{6}{|c|}{ Log Marginal Cost VAR } \\
\hline$\phi_{1}$ (constant) & 0.291 & 3.211 & 0.069 & 0.286 & -4.684 & 5.896 \\
\hline$\phi_{2}\left(\ln C_{i t-1}\right)$ & 0.551 & 0.244 & 0.554 & -0.060 & 0.152 & 0.946 \\
\hline$\phi_{3}\left(\omega_{i t-1}\right)$ & 0.314 & 0.383 & 0.311 & 0.020 & -0.306 & 0.942 \\
\hline$\phi_{4}($ trend $)$ & 0.001 & 0.045 & 0.001 & 0.080 & -0.071 & 0.076 \\
\hline$\phi_{5}$ (initial capital stock) & -0.003 & 0.105 & -0.004 & 0.062 & -0.170 & 0.169 \\
\hline$\phi_{6}($ exported, t-1) & -0.146 & 0.387 & -0.145 & -0.042 & -0.788 & 0.490 \\
\hline$\phi_{7}$ (imported intermediates, t-1) & -0.098 & 0.403 & -0.104 & 0.029 & -0.764 & 0.557 \\
\hline$\vartheta_{1}^{C}\left(\ln C_{i 1}\right)$ & -0.799 & 1.382 & 0.255 & 0.435 & -0.267 & 0.954 \\
\hline \multirow[t]{2}{*}{$\vartheta_{1}^{c}\left(\omega_{i 1}\right)$} & 0.286 & 0.384 & -0.788 & -0.064 & -3.129 & 1.433 \\
\hline & \multicolumn{6}{|c|}{ Covariance Matrix } \\
\hline $\begin{array}{l}L_{11} \\
\Gamma\end{array}$ & 0.943 & 0.127 & 0.931 & 0.532 & 0.755 & 1.168 \\
\hline$\Sigma_{12}$ & 0.010 & 0.093 & 0.010 & 0.009 & -0.143 & 0.164 \\
\hline$\Sigma_{22}$ & 1.004 & 0.137 & 0.992 & 0.535 & 0.802 & 1.245 \\
\hline
\end{tabular}


TABLE 2:

Descriptive Statistics on Performance Measures (Colombian Pulp Mills)

\begin{tabular}{|c|c|c|c|c|c|c|}
\hline & $\Delta U_{j}$ & $\Pi_{j}$ & $\Delta \sum_{k \neq j} \Pi_{k}$ & $\Delta U_{j}+\Pi_{j} \Delta \sum_{k \neq j} \Pi_{k}$ & \multirow{2}{*}{$\ln C_{j}$} & \multirow{2}{*}{$\omega_{j}$} \\
\hline & $K_{j}$ & $\overline{K_{j}}$ & $K_{j}$ & $K_{j}$ & & \\
\hline Mean & 0.065 & 0.071 & -0.221 & -0.085 & -3.198 & 1.868 \\
\hline Median & 0.004 & 0.067 & -0.156 & -0.057 & -3.252 & 1.886 \\
\hline Std. Dev. & 0.134 & 0.041 & 0.222 & 0.147 & 0.496 & 0.279 \\
\hline Skewness & 12.516 & 2.082 & 4.752 & 7.266 & -0.208 & -0.026 \\
\hline
\end{tabular}

TABLE 3:

Correlations of Performance Measures (Colombian Pulp Mills)*

\begin{tabular}{|c|c|c|c|c|c|c|c|}
\hline & $\frac{\Delta U_{j}}{K_{j}}$ & $\frac{\Pi_{j}}{K_{j}}$ & $\frac{\Delta \sum_{k \neq j} \Pi_{k}}{K_{j}}$ & $\frac{\Delta U_{j}+\Pi_{j}}{K_{j}}+\frac{\Delta \sum_{k \neq j} \Pi_{k}}{K_{j}}$ & $\ln C_{j}$ & $\omega_{j}$ & $\widetilde{\phi}_{j}$ \\
\hline$\frac{\Delta U_{j}}{K_{j}}$ & 1.000 & 0.322 & -0.488 & -0.002 & -0.314 & 0.536 & -0.153 \\
\hline$\frac{\Pi_{j}}{K_{j}}$ & & 1.000 & -0.413 & 0.003 & -0.441 & 0.152 & 0.600 \\
\hline$\frac{\Delta \sum_{k \neq j} \Pi_{k}}{K_{j}}$ & & & 1.000 & 0.699 & 0.466 & 0.194 & 0.073 \\
\hline $\begin{array}{l}\frac{\Delta U_{j}+\Pi_{j}}{K_{j}} \\
+\frac{\Delta \sum_{k \neq j} \Pi_{k}}{K_{j}}\end{array}$ & & & & 1.000 & 0.186 & 0.435 & 0.220 \\
\hline $\ln C_{j}$ & & & & & 1.000 & 0.201 & 0.022 \\
\hline$\omega_{j}$ & & & & & & 1.000 & 0.238 \\
\hline$\widetilde{\phi}_{j}$ & & & & & & & 1.000 \\
\hline
\end{tabular}

* All variables are purged of annual time effects. Productivity normalizations are based on Caves et al (1982). 
FIGURE 1:

EfFects of Producer Trade on Quality and Marginal Cost Trajectories
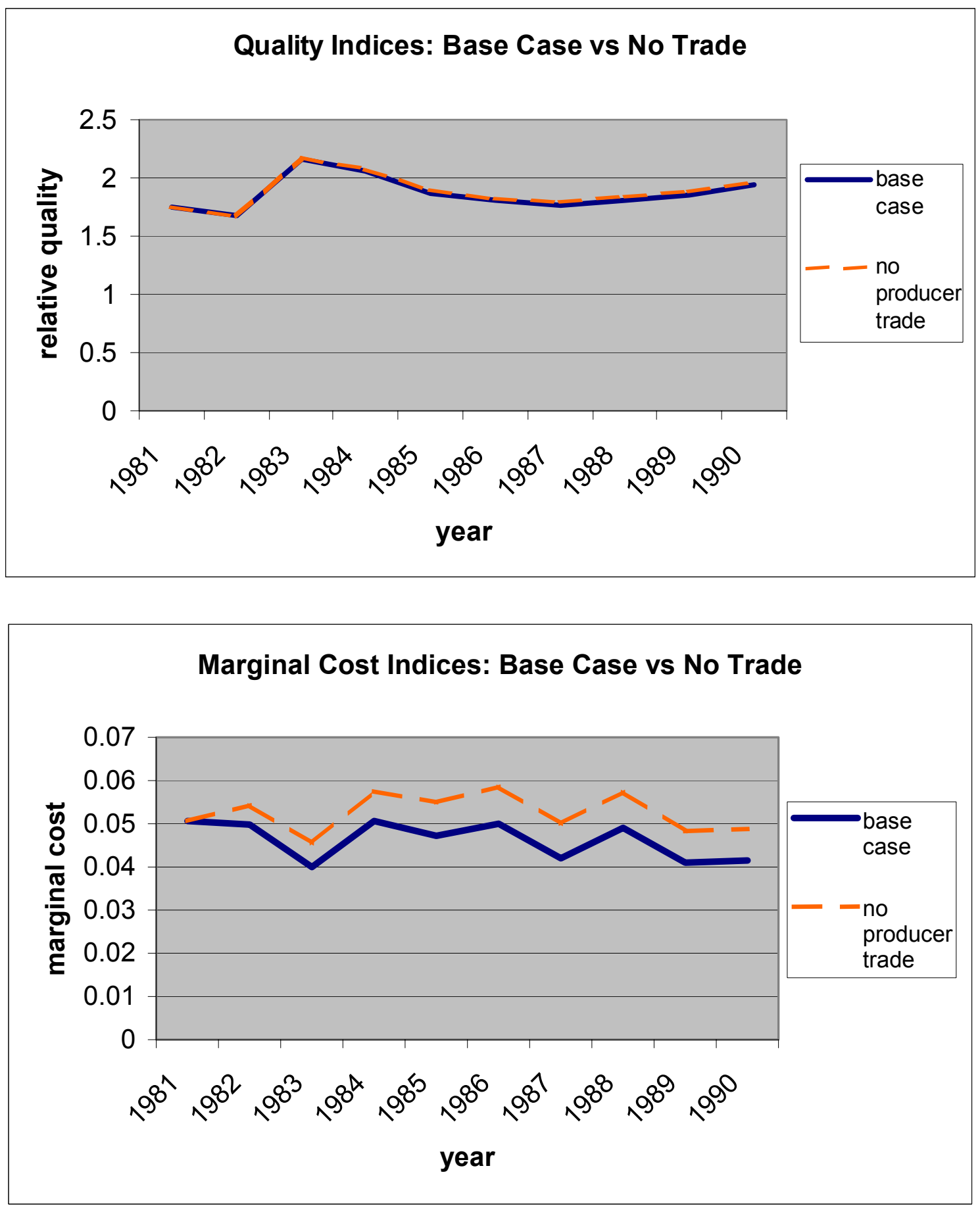
Figure 2: Effects of Producer Trade on Welfare Measures
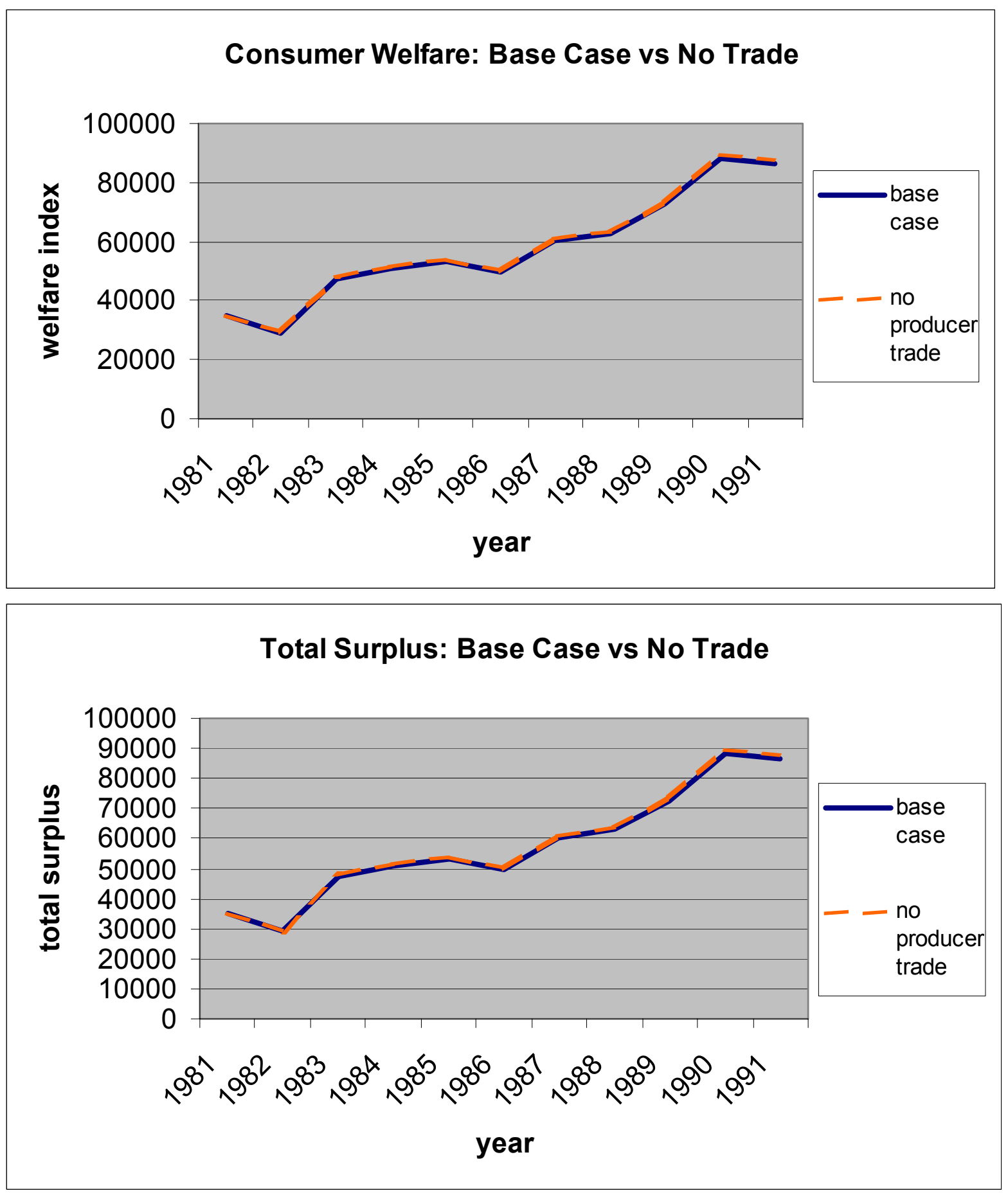
FIGURE 3:

Effects of Producer Trade on Traditional Performance Measures

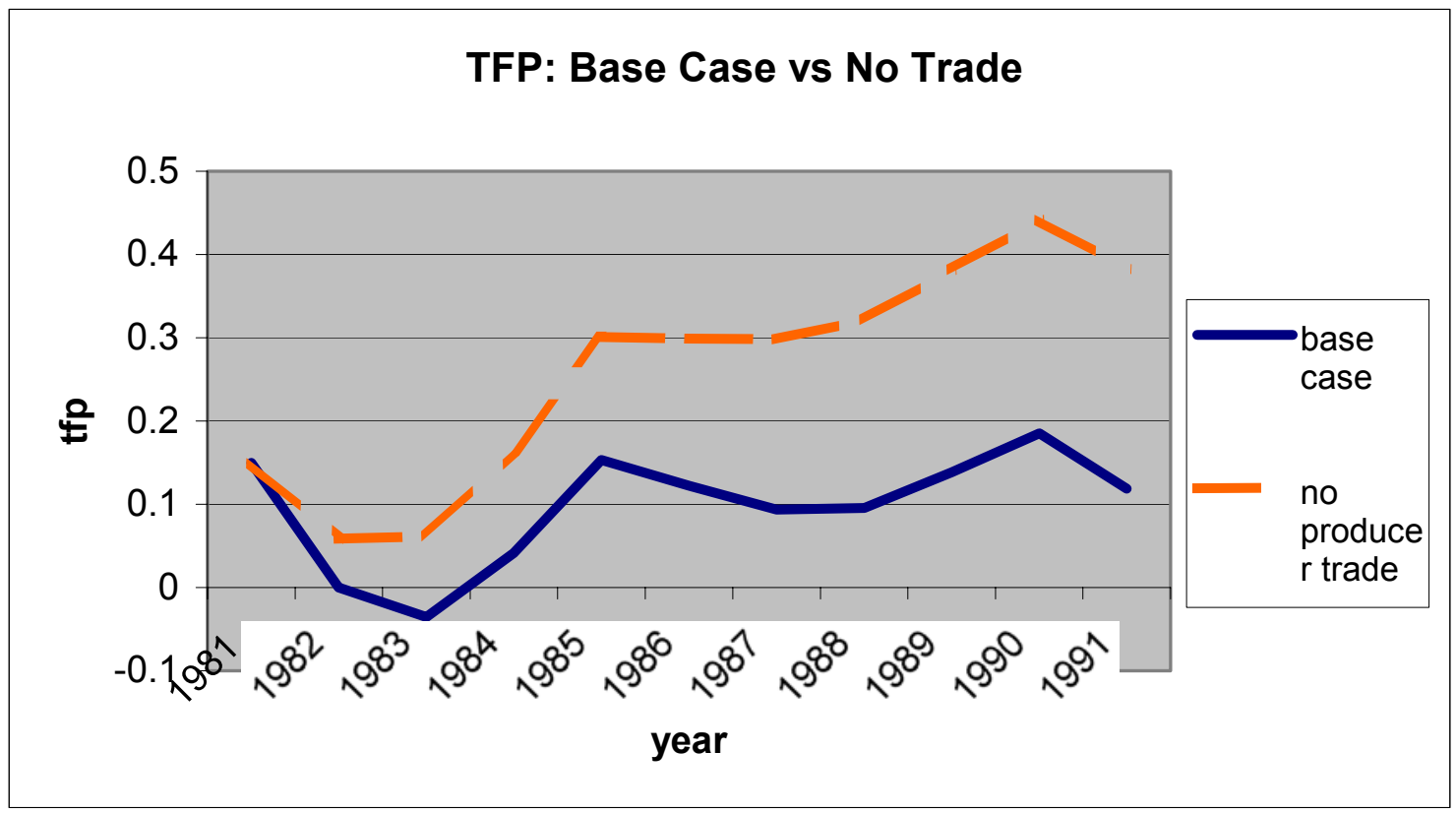

